\title{
LA IGLESIA CONQUENSE EN LA EDAD MEDIA. ESTRUCTURA INSTITUCIONAL Y RELACIONES DE PODER
}

\author{
JORGE DÍAZ IBÁÑEZ \\ Universidad Complutense de Madrid
}

\begin{abstract}
SUMARIO
I. Estructura institucional de la Iglesia conquense: 1. Fundación de la diócesis. 2. El obispo. 3. El cabildo catedralicio. 4. El clero parroquial. 5. El clero regular. 6. Los hospitales y el desarrollo de la caridad. 7. El diezmo.- II. Relaciones de poder: 1. Relaciones con la monarquía castellana. 2. Relaciones intraeclesiales. 3. Relaciones con la sociedad local.- Conclusión.
\end{abstract}

El trabajo que a continuación se presenta tiene como objeto exponer en apretada síntesis las conclusiones fundamentales de las investigaciones que durante los últimos años he llevado a cabo sobre la Iglesia de Cuenca en la Edad Media, desde fines del siglo XII hasta comienzos del XVI ${ }^{1}$. El análisis se centrará en dos cuestiones primordiales. Por un lado, estudiaremos cuáles fueron las bases institucionales de la Iglesia de Cuenca durante la Edad Media, y por otra parte analizaremos el papel que la Iglesia conquense desempeñó, en cuanto que estructura de poder institucionalizada, dentro del

\footnotetext{
'Todo ello fue objeto de mi Tesis Doctoral, defendida en febrero de 1996 en la Facultad de Geografía e Historia de la Universidad Complutense de Madrid bajo el título "La Iglesia de Cuenca en la Edad Media. Siglos XII-XV. Estructura institucional y relaciones de poder". La dirección corrió a cargo del Dr. José Manuel Nieto Soria, catedrático de Historia Medieval en la citada Universidad.

"Anuarion de Estudios Medievales", 30/1 (2(K))
} 
conjunto de la sociedad conquense y castellana bajomedieval y en el marco del complejo entramado de relaciones de poder propio de aquellos siglos.

Primeramente, y como punto de partida, debe constatarse el hecho de que resulta imposible comprender en su máxima dimensión los fenómenos eclesiásticos al margen de la realidad social que los condiciona y de la que forman parte, entendida esta realidad social en su más amplio sentido. De este modo, la Historia de la Iglesia viene a integrarse dentro del extenso ámbito de la Historia social.

Partiendo de esta premisa básica, se ha considerado como una cuestión primordial de análisis el estudio del papel desempeñado por la Iglesia de Cuenca durante la Edad Media en el marco de los complejos procesos de interacción social, de cara a determinar en qué medida su trayectoria histórica se vio condicionada por sus relaciones con otros grupos sociales o incluso dentro de los propios cuadros eclesiásticos, relaciones a través de las cuales la Iglesia conquense y las diversas jerarquías que la integraban manifestarían su capacidad para la consecución de determinados

fines, a la vez que también se verían afectadas en gran medida por los objetivos que el resto de instituciones y grupos sociales aspiraban a lograr. Esta dialéctica de intereses nos introduce de lleno en el terreno de las relaciones de poder.

Pero, a su vez, el análisis detallado de estas últimas hace necesario estudiar previamente la estructura institucional de la Iglesia conquense, pues sólo conociendo dicha estructura es posible entender en profundidad las relaciones de poder protagonizadas por las diversas jerarquías integrantes de la Iglesia de Cuenca, en el sentido de que estas relaciones tendrán su ámbito de plasmación concreta en el marco de una estructura eclesiástica institucionalizada.

\section{ESTRUCTURA INSTITUCIONAL DE LA IGLESIA CONQUENSE}

\section{Fundación de la diócesis}

Conquistada la ciudad de Cuenca en septiembre de 1177 por el rey castellano Alfonso VIII, dentro del contexto de las importantes campañas reconquistadoras protagonizadas por este monarca, muy pocos años después 
se llevaría a cabo la fundación de una nueva diócesis con sede en $\mathrm{Cuenca}^{2}$, como símbolo de la societas christiana que en adelante habría de ser predominante en los nuevos territorios incorporados a la Corona castellana.

La autorización pontificia para esta fundación sería otorgada por el papa Lucio III a Alfonso VIII y al primer obispo electo don Juan Yáñez mediante sendas bulas fechadas, casi con completa seguridad, en Velletri a 1 de junio de de 1182 , a través de las cuales el pontífice facultó al monarca y al electo para que se anexionasen las antiguas sedes visigodas de Ercávica y Valeria a la de nueva creación de $\mathrm{Cuenca}^{3}$. $\mathrm{Al}$ año siguiente, mediante una nueva bula emitida el 15 de mayo de 1183, Lucio III autorizaría a don Juan Yáñez para instituir el nuevo cabildo catedralicio y organizar las iglesias de Cuenca ${ }^{4}$.

En el proceso fundacional el pontífice actuó en todo momento secundando las iniciativas del monarca castellano y del arzobispo de Toledo, sin poner ninguna objección por el hecho de que la nueva creación diocesana contraviniese algunos aspectos de la tradicional organización eclesiástica peninsular procedente de la época visigoda, organización que ya se había visto alterada con motivo de anteriores fundaciones. En adelante, el nuevo obispado conquense sería sufragáneo de la metrópoli toledana.

Ante todo, la creación de la nueva diócesis debe ser interpretada no simplemente como una fase más en el proceso de reorganización eclesiástica peninsular, sino también como una forma de inclusión de las tierras recién conquistadas en el juego de intereses de dos poderes que aparecen como complementarios, el del rey de Castilla y el del arzobispo de Toledo. En este sentido es muy importante tener en cuenta que, a partir del momento de la fundación, Alfonso VIII y sus sucesores van a encontrar en los obispos de Cuenca colaboradores asiduos e interesados en una actividad de importancia fundamental para el desarrollo político del reino de Castilla: la repoblación de las tierras recién incorporadas. Así, la fundación del nuevo obispado, sin negar su significación desde un punto de vista estrictamente eclesiástico,

\footnotetext{
'Sobre ello puede verse: J.M. NIETO SORIA, La fundación del obispado de Cuenca, "Hispania Sacra", XXXIV (1982), pp. 111-132.

${ }^{3}$ Archivo Catedralicio de Cuenca (ACC), caj. 1, n ${ }^{\circ} 1$ y 2. La transcripción de estas bulas aparece recogida en: A. CHACón Gómez-MONEDERo, Las bulas de fundación del obispado de Cuenca, en "Cuenca" (revista de la Diputación Provincial de Cuenca), 25/26 (1985), docs. n" $1-2$.

${ }^{+}$ACC, caj. 1, n 3. A. CliACÓN, op. cit., doc. 3.
} 
también debe interpretarse como un hecho de marcada relevancia política, social y económica.

Poco a poco, y de forma indisolublemente unida al proceso repoblador, se iría configurando una red parroquial rural estructurada en arcedianatos, arciprestazgos y vicarías, definiéndose de este modo los límites de la nueva diócesis. En cuanto a éstos, por el lado oriental llegarían hasta Moya, ya en la frontera con el reino de Valencia y el obispado de Albarracín, así como hasta las proximidades de Requena y Utiel, que finalmente pasaron a formar parte de la diócesis tras su conquista en 1238. El extremo sur vendría dado por la localidad de La Roda, limitando desde mediados del siglo XIII con el nuevo obispado de Cartagena. En lo que se refiere al sector occidental, éste llegaría hasta Santa Cruz de La Zarza, ya en los límites con la archidiócesis de Toledo, mientras que, finalmente, el límite norte lo marcarán el río Tajo y el obispado de Sigüenza. Estos límites, una vez establecidos, se mantendrán durante siglos.

Ya desde los primeros momentos quedaría patente la marcada jerarquización que siempre hubo dentro del estamento clerical conquense. Así, la cúpula estará representada por el obispo y cabildo catedralicio, este último a su vez fuertemente jerarquizado en su seno. El siguiente escalafón vendría dado por los clérigos beneficiados de las parroquias de Cuenca y Huete, muy pronto agrupados en sendos cabildos para la defensa de sus intereses, mientras que un nivel inferior fue el constituído por los clérigos beneficiados rurales que normalmente estaban en desventaja de privilegios con respecto a los anteriores. Los servidores del cabildo catedralicio, capellanes, clero no beneficiado y familiares de canónigos constituyeron el escalafón más bajo de esta jerarquía eclesiástica. A todo ello, además, hay que unir una importante representación del clero regular que irá en aumento a medida que avance la Baja Edad Media.

\section{El obispo}

La cabeza y máxima autoridad eclesiástica del sistema de organización diocesana era el obispo. Durante las centurias medievales la sede

\footnotetext{
${ }^{5}$ Un análisis mucho más detallado de la institución episcopal conquense es el que queda recogido en mi artículo El poder episcopal en la diócesis de Cuenca durante la Edad Media, "Espacio, Tiempo, Forma. Historia Medieval". 9 (1996), pp. 41-88.
} 
episcopal conquense estuvo ocupada por un total de 31 prelados $^{6}$, desde don Juan Yáñez, que ya era electo en $1178^{7}$, hasta el cardenal de San Jorge don Rafael Riario, obispo absentista entre 1493 y 1518.

Los factores y circunstancias que incidieron en la designación de estos prelados fueron de lo más diversos y, junto a motivaciones estrictamente eclesiásticas, la mayoría de las veces serían mucho más determinantes factores de carácter político y social que estaban muy en relación con la propia dinámica evolutiva de la Iglesia occidental y con el desarrollo histórico de la Realeza y sociedad castellana. De este modo, en la elección de los obispos de Cuenca durante la Edad Media, junto al escaso papel que en la práctica, y sólo durante el siglo XIII, desempeñó el cabildo catedralicio, fue mucho más determinante el que jugaron la Monarquía castellana, el Papado y, en las etapas iniciales, los arzobispos de Toledo.

La autoridad episcopal en el terreno eclesiástico quedaría plasmada en los tres tradicionales poderes del obispo que también ejercieron los prelados conquenses: poder de orden, poder de magisterio y poder de jurisdicción. De esta última potestad, la jurisdiccional, se derivaban algunos de los derechos del obispo sobre el clero diocesano, tales como las procuraciones de visita, el catedrático ${ }^{8}$ y la luctuosa ${ }^{9}$. Los obispos de Cuenca legislaron en materia eclesiástica a través de diversos estatutos, que desde la segunda mitad del siglo XIV se promulgarían fundamentalmente en los sínodos diocesanos. Pero casi siempre fueron los vicarios generales del obispo quienes administraron justicia en su nombre, existiendo además, en un nivel inferior, la potestad jurisdiccional ejercida por el deán y los

\footnotetext{
${ }^{6}$ Un análisis de los aspectos fundamentales del pontificado de cada uno de los obispos medievales conquenses queda recogido en mi artículo Episcopologio medieval conquense. "Hispania Sacra", en prensa. 403.

${ }^{7} \mathrm{~J}$. González, El reino de Castilla en la época de Alfonso VIII, Madrid, 1960, vol. I, p.

${ }^{8}$ El más representativo de estos derechos era el llamado impuesto del catedrático. El pago anual y forzoso de este tributo lo hacían los clérigos en reconocimiento del señorío exclusivo del obispo sobre ellos, y hasta tal punto era importante dicho pago que el obispo podía condicionar su intervención en defensa de los privilegios conculcados a cualquier clérigo precisamente al pago de este tributo.

${ }^{9}$ Esta tributación inicialmente consistió en la entrega a la mesa episcopal de una mula o rocín de montar y de un vaso, cifo o taza de plata de los bienes de cada canónigo o clérigo de la diócesis cuando tenía lugar la muerte de éstos. No obstante, los obispos de Cuenca no tardarían en suprimir el pago de este impuesto a cambio de la entrega de una pequeña cantidad simbólica de dinero.
} 
arcedianos, así como por los arciprestes y vicarios rurales y sus respectivos lugartenientes, en este último caso muy limitada.

Por otro lado, y gracias a las donaciones regias del proceso de dotación inicial de la diócesis, durante el reinado de Alfonso VIII, los obispos de Cuenca pronto lograrían hacerse con algunos señoríos jurisdiccionales, cuyos habitantes y concejos pasaron a ser vasallos episcopales obligados a pagar anualmente determinados tributos en moneda y en especie al prelado, su señor. Estos señoríos donados por el rey, y sobre los que el cabildo catedralicio también ejercería un cierto grado de potestad, fueron los siguientes: los castillos de Peñas Alcatenas y Piedras Luches ${ }^{10}$, que en el siglo XIV perderían importancia para la Iglesia conquense; las aldeas de Huerta" $^{11}$ y Abia ${ }^{12}$; los castillos de Monteagudo y Paracuellos ${ }^{13}$; y la villa de Pareja con sus aldeas ${ }^{14}$, que pronto se convertiría en el principal señorío episcopal conquense. Gracias a estas donaciones, Alfonso VIII lograría la colaboración de los obispos de Cuenca en la repoblación de dichos lugares. Además, también existieron otros dos señoríos episcopales que aparecen documentados como tales desde fines del siglo XV, las pequeñas aldeas de Poveda y Vindel, sobre las que se desconoce el momento exacto en que pasaron a ser señoríos de los obispos conquenses.

En lo que respecta al patrimonio y rentas de la mesa episcopal conquense, separada ya desde los momentos iniciales de la mesa capitular, los datos que han llegado hasta nosotros sobre la cuestión son francamente escasos. Desde luego el diezmo pronto se perfiló como la principal fuente de ingresos de la mesa episcopal. Seguirían en importancia las rentas procedentes de los señoríos episcopales y otros bienes rurales propiedad de los prelados, debiendo destacarse el relieve inicial adquirido por los molinos hidráulicos ${ }^{15}$. En un nivel inferior tendríamos las rentas sobre salinas y portazgos, que variaron a lo largo del tiempo. El complemento a todo lo anterior venía dado por el impuesto del catedrático que pagaba todos los

\footnotetext{
"ACC, Estatutos, privil. VII, ff. 2v-3r (24-II-1182).

"ACC, caj. 1, n" 6 (14-XI-1183).

${ }^{12} \mathrm{ACC}$, Estatutos, privil. X, f. 3r (24-XII-1183).

${ }^{13} \mathrm{ACC}$, caj. 1, n' 10 (12-IV-1187).

${ }^{1+}$ ACC, Estatutos, f. 3v (11-IV-1198).

${ }^{15}$ En lo tocante a este punto cabe destacar el trabajo de S. AgUadÉ NiETo, Molino hidráulico y sociedad en Cuenca durante la Edad Media (1177-1300). "Anuario de Estudios Medievales". 12 (1982), pp. 241-277.
} 
años el clero diocesano, así como por otros derechos económicos derivados del ejercicio de la jurisdicción episcopal y parte de los donativos y oblaciones que realizaban los fieles en la catedral. En cuanto al patrimonio urbano de la mesa episcopal, parece que su importancia fue insignificante.

Si establecemos una valoración global aproximada sobre la evolución del nivel de rentas episcopales en Cuenca durante estos siglos, llama la atención el enorme y paulatino ascenso que experimentó la mitra conquense con respecto a otras a lo largo de la Baja Edad Media. Así, desde comienzos del siglo XIV el obispo de Cuenca debía pagar a la Cámara Apostólica 500 florines de oro en concepto de servicios comunes ${ }^{16}$, cifra bastante baja que situaba a Cuenca entre las diócesis castellanas de renta poco elevada; en cambio, en 1470 la Cámara Apostólica actualizaría la cantidad que en adelante tendrían que pagar los prelados conquenses en concepto de servicios comunes, estableciéndose en 3000 florines de oro $^{17}$, lo que situaba a Cuenca entre las mitras con un nivel de rentas medio-alto. Hacia 1479, poco antes de morir, el obispo Antonio Jacobo de Veneris arrendaría a su provisor en Cuenca, el protonotario Gabriel Condulmario, los frutos de la mesa episcopal conquense por un valor de 4000 ducados anuales ${ }^{18}$, lo que puede servir como dato orientativo del nivel de rentas de la mitra en esa época. Y situándonos ya en el siglo XVI, cabe destacar que Lucio Marineo Sículo cifraba para el año 1530 las rentas episcopales conquenses en 16.000 ducados anuales, cantidad que situaba a Cuenca entre las mitras de nivel de rentas elevado, tras Toledo, Sevilla, Sigüenza, Santiago, Zaragoza y Burgos $^{19}$.

Otra cuestión muy importante en la evolución histórica de la institución episcopal conquense es la que vino dada por la celebración de sínodos diocesanos. Para la Edad Media hay constancia de que en el obispado conquense se celebraron al menos dieciséis sínodos, lo que muestra que hubo una actividad relevante en este sentido si se compara con el número de sínodos medievales convocados en otras diócesis. Casi todos se reunieron en la catedral conquense o en el señorío de Pareja, y las constitu-

\footnotetext{
${ }^{16}$ Archivio Segreto Vaticano (ASVat), Obligationes et Solutiones, vol. 1, f. $11 \mathrm{v}$.

${ }^{17}$ Ibidem, vol. 84, f. 110 r.

${ }^{18}$ Archivo General de Simancas (AGS), Registro General del Sello, 15-I-1479, f. 6.

"S. AguAdÉ NiETO, Crisis de subsistencia, rentas eclesiásticas y caridad en la Castilla de la segunda mitad del siglo $X V$. "En la España Medieval", 2 (1982), p. 31.
} 
ciones de ellos emanadas versaron en su conjunto sobre la práctica totalidad de aspectos eclesiásticos, concernientes tanto al clero como a los laicos, susceptibles de ser objeto de legislación por el obispo ${ }^{20}$.

El primer sínodo de cuya celebración tenemos constancia fue el convocado por don Bernal Zafón en 1364. Mucho más intensa fue, sin embargo, la labor realizada por don Juan Cabeza de Vaca, que convocó hasta cinco sínodos, en los años 1399, 1402, 1403, 1404 y 1406, lo cual le convierte en uno de los prelados con mayores inquietudes reformistas de todos los que ocuparon la sede conquense durante la Edad Media, y de hecho las constituciones sinodales por él promulgadas se convertirán en una base fundamental de la producción sinodal conquense posterior. Casi tan intensa fue la actividad desarrollada en este sentido por don Diego de Anaya Maldonado, que convocó cuatro sínodos, en 1409, 1411, 1413 y 1414. En cambio don Álvaro de Isorna durante su largo pontificado conquense sólo celebraría un sínodo, en 1442, manifestando por tanto una escasa preocupación en este sentido. Fray Lope de Barrientos convocó dos sínodos siendo obispo de Cuenca, uno en $1446^{21}$, en el que se promulgarían unas extensas e importantes constituciones, tanto nuevas como compilación de algunas anteriores, y el otro, de menor importancia, en $1457^{22}$. En cuanto a Fray Alfonso de Burgos, durante su breve pontificado conquense celebraría dos sínodos, en los años $1482^{23}$ y $1484^{24}$. Finalmente, el último sínodo medieval fue el convocado por don Pedro de Costa, provisor del cardenal de San Jorge, en $1493^{25}$. Hay que destacar que todos estos sínodos medievales serán la base de los celebrados en la Edad Moderna.

\footnotetext{
${ }^{20}$ La mayor parte de los sínodos sobre los que a continuación se hablará, y salvo alguna excepción, están recogidos en el Libro de Estatutos que se conserva en el Archivo Catedralicio de Cuenca, y actualmente se encuentran en curso de edición dentro de la colección "Synodicon Hispanum", cuya publicación corre a cargo de la Biblioteca de Autores Cristianos.

${ }^{21}$ Biblioteca del Colegio de Santa Cruz de Valladolid, Ms. 340.

"2Ibidem.

${ }^{23}$ Biblioteca del Real Monasterio de San Lorenzo de El Escorial, Ms. M.II.22, f. 2v.

${ }^{24} \mathrm{Las}$ constituciones de este sínodo fueron llevadas a la prensa muy poco tiempo después de su promulgación, y el único ejemplar incunable que ha llegado hasta nosotros de aquella prematura edición es el que actualmente se conserva en la British Library de Londres, con la signatura IB 53403. Un estudio pormenorizado y transcripción de estas constituciones sinodales puede verse en mi trabajo: Fray Alonso de Burgos y el sínodo conquense de 1484, "Hispania Sacra", XLVII (1995), pp. 299-346.

${ }^{25}$ Biblioteca del Colegio de Santa Cruz de Valladolid, Ms. 340.
} 


\section{El cabildo catedralicio}

Tras la institución episcopal, el cabildo catedralicio ocupaba el segundo lugar en la jerarquía eclesiástica conquense ${ }^{26}$. Era un colectivo de clérigos con personalidad jurídica propia plenamente desarrollada en el Derecho Canónico, cuya misión consistió en engrandecer el culto catedralicio mediante la asistencia al rezo de las horas canónicas y a otras funciones litúrgicas, auxiliar al obispo en el gobierno de la diócesis y colaborar en la compleja administración del patrimonio económico de la mesa capitular. Sus integrantes, no siempre presbíteros, poseyeron un beneficio capitular cuya cuantía estuvo en función del prestigio e importancia del cargo ostentado en el cabildo, y a veces también tuvieron beneficios en otros lugares de la diócesis conquense o incluso en otras diócesis. El cabildo catedralicio tenía un sello propio como símbolo de su autoridad, intervenía junto con el obispo en la colación de beneficios capitulares y legislaba a tráves de los estatutos promulgados en numerosas reuniones capitulares.

Contando con la previa autorización pontificia, otorgada por Lucio III el 15 de mayo de $1183^{27}$, muy poco después, el 28 de julio del mismo $a_{n} o^{28}$, el electo don Juan Yáñez instituyó el nuevo cabildo catedralicio, asignándole sus primeras rentas. Por su parte, el obispo San Julián otorgó en 1201 los primeros estatutos capitulares conocidos ${ }^{29}$. Formado inicialmente por canónigos regulares, como muy tarde a mediados del siglo XIII el cabildo catedralicio conquense ya estaría plenamente secularizado.

Fuertemente jerarquizado en su seno desde los primeros momentos, a su cabeza estaban las llamadas dignidades o personas, que inicialmente fueron ocho: prior, que en 1215 ya había sido sustituído por el deán ${ }^{30}$; arcediano de Cuenca; arcediano de Huete, que ya existía antes de la conquista de Cuenca como dignidad dependiente de la Iglesia de Toledo; arcediano de Alarcón; arcediano de Cañete, que en 1215 ya había sido

\footnotetext{
${ }^{26}$ Sobre los orígenes y desarrollo inicial de esta institución, puede verse mi trabajo $\mathrm{El}$ cabildo catedralicio conquense en el siglo XIII, "Anuario de Estudios Medievales", 27/1 (1997), pp. 315-345.

${ }^{27} \mathrm{ACC}$, caj. $1, \mathrm{n}^{0} 3$.

${ }^{28} \mathrm{ACC}$, caj. $1, \mathrm{n}^{\circ} 4$.

${ }^{29} \mathrm{ACC}$, caj. 2, $\mathrm{n}^{\mathrm{0}} 30$.

${ }^{30} \mathrm{ACC}$, caj. 3, no 41 .
} 
sustituído por el de Moya ${ }^{31}$; chantre; maestrescuela y tesorero. Posteriormente, ya en el siglo XV, se instituyeron las nuevas dignidades de abad de Santiago y abad de la Sey ${ }^{32}$.

Seguía en importancia el cabildo de canónigos, la corporación catedralicia por excelencia, del que casi siempre formaron parte las dignidades en función de la posesión de alguna canonjía. Inicialmente el número de canónigos fue de dieciséis, pero más tarde aumentaría hasta quedar establecido en veintiséis canónigos, manteniéndose también así en la Edad Moderna.

Finalmente estaban los racioneros y mediorracioneros o compañeros. De cara a evitar su aumento excesivo, en 1251 el cardenal Gil de Torres, legado pontificio, estableció que el número de racioneros fuese de diez y el de mediorracioneros de doce ${ }^{33}$, debiendo también destacarse la estabilidad posterior de este número de beneficios, que en el siglo XVII no había variado.

Miembros de una auténtica élite eclesiástica urbana, muchos de los integrantes del cabildo catedralicio, aunque no todos, procedían de algunas de las más conspicuas familias de la oligarquía urbana conquense, que pronto vieron en esta institución una excelente plataforma de promoción social. Así, algunos miembros de los linajes Albornoz - entre ellos el futuro cardenal don Gil-, ya desde el siglo XIV, Carrillo y Hurtado de Mendoza, sobre todo a partir del siglo $\mathrm{XV}$, ostentarán canonjías y fundamentalmente dignidades en el cabildo catedralicio conquense, lo que estaba acorde con la elevada posición social que tenían en la ciudad. Por otro lado, también consiguieron acceder al cabildo catedralicio, en especial desde el siglo XV, algunos personajes pertenecientes a ciertas familias hidalgas de Cuenca, como eran los Cañizares, Chirino, Cañaveras, Molina, Dones, Torralba o Valera; estos hidalgos a veces ocuparon canonjías, raciones y mediasrraciones, pero casi nunca dignidades.

En cuanto al beneficio capitular, estaba integrado por ingresos procedentes de diversas fuentes de renta, siendo su cuantía económica mayor

\footnotetext{
${ }^{31}$ ACC, caj. 2, no 40. Se trata de una concordia, fechada el 25 de abril de 1215 , entre el obispo de Cuenca don García Ruiz y los clérigos de las aldeas del término de Huete. Entre los confirmantes figura la suscripción autógrafa del arcediano de Moya, "Modiensis archidiaconus».

${ }^{32} \mathrm{ACC}$, caj. O, n" 7.

${ }^{33} \mathrm{~J} . \mathrm{M}$. NIETO SORIA, El intervencionismo pontificio sobre la Iglesia conquense en el siglo XIII, "Hispania", XLV/159 (1985), pp. 54-55.
} 
o menor en función del grado jerárquico ocupado en el cabildo. En general, los componentes del beneficio fueron uno o varios préstamos situados sobre las rentas decimales en algunas parroquias de la ciudad o diócesis, el vestuario estimado en una cuantía determinada de maravedís al año, y una o varias raciones situadas sobre las rentas de la mesa capitular. La percepción del beneficio estaba teóricamente sujeta a toda una serie de normas sobre residencia y cumplimiento de deberes litúrgicos en la catedral que pronto comenzaron a ser precisadas con exactitud. No obstante, frecuentemente algunas de estas normas se quedarían en pura y simple teoría al entrar en juego las numerosas situaciones de absentismo que no tardaron en contar con el respaldo pontificio, fenómeno éste que ya comienza a observarse al menos desde el siglo XIV y que a veces afectaría a la buena marcha del cabildo. Fue por ello por lo que éste tuvo que luchar en ocasiones para evitar el absentismo excesivo y a menudo injustificado de algunos de sus miembros.

La complejidad organizativa del cabildo y del culto catedralicio, en constante aumento a medida que avanzaba la Baja Edad Media, hizo pronto necesaria la presencia cada vez mayor de toda una serie de servidores y auxiliares para el culto, así como de bastantes oficiales para la administración y distribución del patrimonio y rentas de la mesa capitular y para otro tipo de cuestiones ${ }^{34}$. La mayoría de los servidores del cabildo fueron clérigos, y en cuanto a los cargos de oficial, muchos de ellos fueron desempeñados por los propios capitulares. Por otro lado, algunos de los servidores del culto catedralicio llegarían incluso a agruparse formando auténticos colectivos clericales para la defensa de sus intereses, siendo un claro ejemplo de ello el cabildo de capellanes de San Ildefonso y Corpore Christi ${ }^{35}$.

\footnotetext{
${ }^{34}$ Vid. mi artículo Los oficiales y servidores del cabildo catedralicio conquense durante la Edad Media, "Studia Academica" (Revista del Centro Asociado de la UNED en Cuenca), 4 (1997), pp. 169-190.

${ }^{35}$ ACC, Libros de Fábrica, II.10, f. 17r. Este cabildo ya existía al menos desde mediados del siglo XIV.
} 
Respecto al patrimonio del cabildo catedralicio ${ }^{36}$, ya desde los primeros momentos estuvo compuesto por un conjunto de bienes y rentas muy diversos, tanto rurales como urbanos, si bien los ingresos rurales siempre serán los más importantes, en concreto los procedentes de las rentas decimales a que tenía derecho el cabildo. El impulso inicial a este patrimonio vino dado por el proceso de dotación regia, sobre todo durante el reinado de Alfonso VIII, pero pronto comenzaron también las frecuentes donaciones al cabildo por parte de sus propios miembros, los obispos conquenses, otros eclesiásticos y numerosos laicos, tanto nobles como simples vecinos de Cuenca, a cambio de la celebración de misas, aniversarios u otros fines litúrgicos, todo lo cual determinó el constante incremento de este patrimonio a lo largo de la Edad Media y siglos posteriores.

Aunque en los momentos iniciales la explotación directa de los bienes y rentas capitulares parece que tuvo un cierto peso, a medida que avance el siglo XIII se irá imponiendo poco a poco un sistema de explotación indirecta mediante arrendamientos que será cada vez más complejo, actuando como arrendatarios tanto los propios canónigos como otros clérigos y numerosos laicos. Las diversas rentas eran percibidas por el mayordomo o mayordomos encargados de su administración y distribución entre los beneficiarios de las mismas según una complicada normativa y, al menos en teoría, según el grado de cumplimiento por parte de los capitulares de todas sus obligaciones.

La propiedades rurales del cabildo catedralicio fueron de diverso tipo y cada vez más variadas conforme avanzó la Baja Edad Media: heredades con o sin casas, viñas, majuelos, hazas, huertos, hocinos, molinos hidráulicos y algunas extensas dehesas para pasto de ganado. En el siglo XIV ya se encontraba plenamente afianzado el sistema de explotación indirecta de estos bienes rurales, predominando sobre todo los censos perpetuos, aunque desde el siglo XV también irán apareciendo algunos arrendamientos a corto o medio plazo de molinos hidráulicos y dehesas.

Respecto a los molinos hidráulicos, durante la Baja Edad Media se observa un importante grado de señorialización de su propiedad, de suerte

\footnotetext{
${ }^{36}$ Sobre esta cuestión, y para los momentos iniciales, puede verse: A. CHACÓN GÓMEzMonedero, El patrimonio rural de la Iglesia de Cuenca. Siglos XII-XIII, en "Cuenca" (revista de la Diputación Provincial de Cuenca), 30 (1987), pp. 51-71, así como J.M. NIETo SORIA, El equipamiento económico de una sede episcopal castellana de nueva creación: Cuenca, 11801280, "Anuario de Estudios Medievales". 12 (1982), pp. 311-340.
} 
que junto al cabildo catedralicio los obispos conquenses y la Orden de Santiago también ejercerán un destacado control sobre los mismos. Hay que destacar además que, junto a los molinos harineros, también habrá una creciente presencia de los batanes, siendo éste un proceso estrechamente relacionado con el desarrollo de la industria textil conquense ${ }^{37}$.

Ya muy a fines de la Edad Media, en 1495, los ingresos que el cabildo catedralicio percibió en dinero procedentes de los censos sobre heredades y propiedades rurales menores y también sobre propiedades urbanas ascendieron a $129.674,5 \mathrm{mrs}$. Por los censos rurales citados se percibieron $34.077 \mathrm{mrs}$., lo que supone un $26,28 \%$ del total, correspondiendo el $73,72 \%$ restante a los bienes urbanos. A su vez, los censos situados sobre bienes rurales menores - huertas, hocinos viñas y majuelos- en los alrededores de Cuenca supusieron 17.031,5 mrs., lo que viene a ser un $49,98 \%$ sobre el total de censos rurales, mientras que por los situados sobre heredades y bienes rurales menores en otros lugares de la Tierra de Cuenca y del obispado se ingresaron $17.045,5$ mrs. correspondientes al $50,02 \%$ restante ${ }^{38}$.

En cuanto a las rentas en especie procedentes del acensuamiento a perpetuidad de los bienes rurales vinculados al Arca de la Limosna, institución asistencial de gran importancia desde el siglo XV y dependiente del cabildo catedralicio, a modo de ejemplo, puede señalarse que en 1515 supusieron un total de 1588,5 almudes de trigo de la medida menor, situados fundamentalmente sobre heredades de la Tierra de Cuenca ${ }^{39}$.

El patrimonio urbano del cabildo catedralicio en la ciudad de Cuenca comenzó su formación a fines del siglo XII, y desde entonces se incrementó constantemente gracias donaciones tanto de capitulares como de otros clérigos y laicos. Estaba constituído ya desde sus inicios por casas y

\footnotetext{
${ }^{37}$ Sobre los molinos hidráulicos puede verse el trabajo de S. AgUAdÉ NIETO, Molino hidráulico y sociedad en Cuenca durante la Edad Media (1177-1300), "Anuario de Estudios Medievales", 12 (1982), pp. 241-277. En cuanto a la industria textil en Cuenca destaca ante todo el trabajo de P. IRADIEl MURUGARREN, Evolución de la industria textil castellana en los siglos XIII-XVI. Factores de desarrollo, organización y costes de la producción manufacturera en Cuenca, Salamanca, 1974.

${ }^{38}$ Archivo Histórico Provincial de Cuenca (AHPC), Desamortización, leg. 249. Se trata de un cuadernillo de 28 folios que contiene la relación de propiedades urbanas y rurales del cabildo catedralicio en 1495. Un análisis detallado de dicho documento aparece en mi trabajo Propiedades censuales del cabildo catedralicio conquense a fines del siglo XV. Un documento para su estudio, "Archivo Conquense", 1 (1998), pp. 43-85.

${ }^{39}$ AHPC, Desamortización, leg. 782.
} 
propiedades comerciales, destacando entre estas últimas las tablas de carnicería $a^{40}$. En cuanto a la forma de explotación, no tardaría en imponerse, ya desde el siglo XIII, el sistema de arrendamiento, actuando como arrendatarios tanto canónigos como otros clérigos y numerosos laicos.

De este modo, tras un constante incremento del patrimonio urbano capitular gracias a numerosas donaciones, se llegaría a la situación que se observa en 1495, año en que el cabildo poseía al menos 211 casas distribuídas a lo largo de toda la ciudad, además de algunas boticas, establos, bodegas, ollerías, tenerías y tablas de carnicería, entre otras propiedades. Ese año los ingresos del cabildo por el arrendamiento de todas estas propiedades urbanas ascendieron a 95.597,5 mrs., cifra, pues, superior a la de los ingresos en dinero percibidos por los censos sobre heredades y propiedades rurales menores. A su vez, de esta renta urbana, el $94,36 \%$ procedía del arrendamiento de casas, correspondiendo el resto a las otras propiedades ${ }^{41}$.

En cuanto al comercio de la carne en la ciudad de Cuenca, el cabildo catedralicio ejerció un fuerte control sobre el mismo desde fines del siglo XII gracias a la posesión de numerosas tablas de carnicería. Pero a lo largo del siglo XIV se desarrollaría una clara competencia al respecto entre la institución capitular y el concejo conquense que evolucionará, ya en la centuria siguiente, hacia una situación casi de monopolio, a través de la cual se impuso un creciente control municipal del mercado de la carne.

Pero, además de las importantes rentas que el cabildo catedralicio obtuvo de la explotación de este patrimonio rural y urbano, la institución capitular también se vio beneficiada por la temprana posesión de toda una serie de privilegios económicos, sobre todo de origen real, así como exenciones diversas, lo cual constituyó un complemento esencial a las antedichas rentas capitulares. Las salinas, y en menor medida los portazgos, aportaron ciertos ingresos al cabildo, que también percibió, aparte del diezmo, otros pequeños derechos eclesiásticos, gozando asimismo de la exención del pago de numerosos pechos reales.

\footnotetext{
${ }^{40}$ En este punto conviene destacar el trabajo de S. AguadÉ NiETo y $\mathrm{M}^{\mathrm{a}}$ D. CABAÑaS GONZÁlEZ, Comercio y sociedad urbana en la Castilla medieval. La comercialización de la carne en Cuenca (1177-1500), "Anuario de Estudios Medievales", 14 (1984), pp. 487-516.

${ }^{41}$ AHPC. Desamortización, leg. 249.
} 


\section{El clero parroquial}

Por debajo de la alta posición jerárquica ostentada por el obispo y cabildo catedralicio se encontraba el clero parroquial que, aún beneficiándose del estatuto de privilegio que se derivaba de su pertenencia al estamento eclesiástico, ocupaba un puesto de mucho menor relieve en el escalafón social.

Desde un primer momento la parroquia quedó constituída como célula básica de organización del territorio diocesano conquense, desarrollándose la estructura parroquial de forma paralela e indisolublemente unida al proceso repoblador ${ }^{42}$. De este modo, la lenta constitución de la extensa red parroquial se iniciaría, ya antes de la fundación del obispado conquense, paralelamente a la repoblación de Huete y su extenso alfoz, organizados como un arcedianato tras su conquista definitiva por Alfonso VII a mediados del siglo XII, y terminaría en sus rasgos esenciales hacia fines del siglo XIII o bien a lo largo de la centuria siguiente, una vez completada la repoblación en las zonas de Requena y Utiel, sin que ello signifique que posteriormente no se produjesen ligeros cambios o se crease alguna nueva parroquia rural.

En la ciudad de Cuenca, ya desde fechas muy tempranas, se establecieron trece parroquias: San Pedro, San Nicolás, San Miguel, Santa María-Santiago (catedral), San Martín, Santa Cruz, San Gil, San Esteban, San Vicente, San Salvador, Santo Domingo, San Juan y San Andrés; ya a comienzos del siglo XV, en 1403, el obispo don Juan Cabeza de Vaca erigió en parroquia la iglesia de Santa María La Nueva, que algunos años atrás se había establecido sobre la antigua sinagoga judía ${ }^{43}$. En cuanto a Huete, las diez parroquias que siempre hubo fueron las siguientes: Santa María de Atienza, Santa María de Castejón, Santa María de Lara, San Nicolás de Medina, San Nicolás de Almazán, Santiago, San Pedro, La Trinidad, San Miguel y San Esteban; además, durante algún tiempo, y antes de mediados

\footnotetext{
${ }^{42} V i d$. mi artículo Orígenes y configuración de la estructura parroquial en la diócesis de Cuenca. Siglos XII-XVI, "Studia Academica", 7 (1999), pp. 125-170.

${ }^{43}$ De gran interés resulta a este respecto el trabajo de D. PÉrEZ RAMíREZ, La sinagoga de Cuenca, iglesia de Santa Maria La Nueva, en "Cuenca", 19/20 (1982), pp. 47-78.
} 
del siglo XIV, también existió en Huete otra parroquia más, la de San Marcos, que estaba situada en el castillo de la villa ${ }^{44}$.

La estructura diocesana conquense se adaptó a las características geográficas del territorio. Así, en la zona de la Serranía, dada su gran extensión, hubieron de establecerse dos arcedianatos: el de Cuenca, en el sector occidental, y el de Cañete-Moya en la parte oriental. Por otro lado, el arcedianato de Huete abarcó en líneas generales el territorio de La Alcarria conquense, mientras que la zona de llanura de La Mancha situada dentro de los límites diocesanos se correspondería con el arcedianato de Alarcón.

Pero, además, el obispado conquense también se subdividió durante la Edad Media en los ocho arciprestazgos de Cuenca, Huete, Alarcón, Moya, Requena, El Castillo (de Garcimuñoz), Uclés y Pareja, cuya cabeza estaba en los centros de poblacion más importantes de la diócesis. Respecto al arciprestazgo de Huete, existente desde los momentos iniciales, antes del siglo XIV dejó de serlo para transformarse en vicaría, pasando desde 1406 a ser de nuevo arciprestazgo ${ }^{45}$. Por otro lado, las vicarías medievales del obispado conquense constituyeron otras circunscripciones eclesiásticas de menor relieve, siendo las siguientes: Cañete, Utiel, Belmonte, Montalbo, Iniesta, Huerta y Huete durante el tiempo que dejó de ser arciprestazgo. Hay que destacar que los arciprestes y vicarios rurales, más que los arcedianos, fueron quienes desempeñaron un papel de mayor importancia en la administración eclesiástica del territorio diocesano.

Las parroquias eran el centro donde los clérigos ejercían la cura pastoral sobre los laicos, constituyendo asimismo un eje importante en torno al cual giraba la vida social de cada comunidad de feligreses. Sometidas a la jurisdicción episcopal, en teoría cada cierto tiempo debían ser visitadas por el obispo o sus vicarios, si bien los primeros testimonios detallados que han llegado hasta nosotros sobre la realización de estas visitas datan ya de fines del siglo XV.

Junto a las simples parroquias, la única Colegiata que hubo en el obispado conquense fue la de Belmonte, instituída sobre la primitiva parroquia de San Bartolomé por el papa Pío II en 1459, a instancias del

\footnotetext{
${ }^{+4}$ Un análisis y colección documental sobre la vida eclesiástica en Huete durante la Edad Media quedan recogidos en mi libro El clero y la vida religiosa en Huete durante la Edad Media. Estudio y colección documental, Cuenca, 1996.

${ }^{45}$ ACC, Estatutos, f. 60v.
} 
marqués de Villena don Juan Pacheco, que en adelante sería su patrono ${ }^{46}$. Además, también hubo en la diócesis numerosas iglesias, capillas y ermitas de carácter no parroquial.

En cada parroquia podía haber uno o más clérigos adscritos a ella, pudiendo ser tanto clérigos beneficiados como no beneficiados, caso este último el de los capellanes que frecuentemente se encargaron de la cura animarum a cambio de un modestísimo salario. Junto a los beneficios servideros, que conllevaban obligación de residencia, también había otros no servideros, tal como sucedía con los prestimonios parroquiales que fueron concedidos por el papa a numerosos clérigos. La cuantía económica de todos estos beneficios variaba mucho según cada caso. A su vez, en cada parroquia podía haber clérigos de órdenes mayores o menores, según la labor que desempeñasen.

De cara a la defensa de sus intereses, ya desde fechas muy tempranas se constituyeron en la ciudad y diócesis de Cuenca toda una serie de asociaciones de clérigos parroquiales que se agrupaban formando un cabildo, con un abad a su frente. Los dos colectivos clericales de este tipo más importantes que hubo en el obispado conquense durante la Edad Media fueron el cabildo de clérigos beneficiados de Cuenca y el cabildo de clérigos beneficiados de Huete $^{47}$, poseyendo cada uno un patrimonio tanto rural como urbano de cierto relieve que se formó gracias a las donaciones recibidas, y cuya explotación se realizaría casi siempre mediante censos perpetuos. Pero, aparte de estos dos amplios colectivos clericales urbanos, también hubo otros de carácter rural distribuídos por toda la diócesis, a lo que habría que añadir algunos cabildos exclusivamente de capellanes parroquiales.

En cuanto a los ingresos económicos de las parroquias y el clero a ellas adscrito, procedían sobre todo del cobro de derechos eclesiásticos, fundamentalmente diezmos y primicias, y en menor medida derechos funerarios, ofrendas a pie de altar y otros donativos diversos, a lo que se unían las rentas provenientes del arrendamiento de los bienes que eran entregados a algunas iglesias para la dotación de servicios religiosos.

\footnotetext{
${ }^{\text {th }}$ Sobre la Colegiata de Belmonte debe destacarse el trabajo de L. ANDÚJAR ORTEGA, Belmonte, cuna de fray Luis de León. Su Colegiata, Cuenca, 1986.

${ }^{47}$ Casi toda la documentación referente a estos dos importantes colectivos clericales se encuentra recogida en el Archivo Histórico Provincial de Cuenca, en sus secciones de Pergaminos y Desamortización, tratándose en su mayor parte de documentos de carácter económico.
} 


\section{El clero regular}

Junto al clero secular, también hubo en el obispado conquense una importante representación del clero regular, tanto en sus ramas masculina como femenina. Tras la fundación del monasterio cisterciense de Santa María de Monsalud $^{48}$, el más antiguo de la diócesis de Cuenca, establecido algunos años antes de la propia fundación del nuevo obispado, se irían creando poco a poco otros monasterios pertenecientes a diversas órdenes en los centros urbanos de Cuenca y Huete y en otros enclaves del territorio diocesano, desarrollándose este proceso durante el siglo XIII y, más intensamente, en las dos centurias siguientes.

De este modo, si establecemos una valoración global sobre la presencia de las diversas órdenes religiosas en el obispado conquense durante el conjunto de la Edad Media, en primer lugar hay que destacar a la Orden franciscana, tanto en su rama masculina como femenina, como la más implantada a través de un mayor número de monasterios ${ }^{49}$. Siguen en importancia numérica los monasterios de dominicos, agustinos y las órdenes de redención de cautivos - mercedarios y trinitarios-, situándose en último término las órdenes de San Benito, Císter y algunas otras de menor entidad escasamente representadas. Asimismo, hay que destacar el progresivo desarrollo e implantación que, fundamentalmente desde el siglo XV, irá adquiriendo la reforma observante en algunos monasterios de Órdenes mendicantes y agustinos, proceso que contaría con el apoyo pontificio, regio y nobiliario.

\footnotetext{
${ }^{48}$ El único monasterio cisterciense de la diócesis de Cuenca era el de Monsalud, fundado en la segunda mitad del siglo XII. Un análisis detallado de la evolución histórica de este monasterio queda recogido en mi artículo Santa María de Monsalud. Reconstrucción histórica de un cenobio cisterciense (siglos XII-XVI), "Cistercium", 201 (1995), pp. 357-474.

${ }^{49}$ Sobre ello puede verse mi trabajo, Monasterios franciscanos en la diócesis de Cuenca durante la Edad Media. "Archivo Ibero-Americano", 58 (1998), pp. 311-336.
} 


\section{Los hospitales y el desarrollo de la caridad ${ }^{50}$}

Desde poco después de la fundación del nuevo obispado, y de forma más intensa a partir del siglo XIV, también se desarrolló una importante red hospitalaria y asistencial en la ciudad y diócesis de Cuenca, lo que fue posible gracias al impulso tanto eclesiástico como de los laicos, siendo éste un fenómeno que estuvo en plena consonancia con el proceso de encuadramiento institucional de la asistencia al pobre que también se observa en Castilla y en el resto de Occidente durante los últimos siglos de la Edad Media. Junto a los hospitales, algunos de los cuales dependieron de cofradías benéficas, debe destacarse el importante papel que desde el siglo XV desempeñaría el Arca de la Limosna, institución caritativa vinculada al cabildo catedralicio.

\section{El diezmo}

En lo referente a las pautas básicas de organización del fisco decimal durante la Edad Media, hay que señalar que en la diócesis conquense la distribución de los diezmos se realizaba en principio a partir de la regla general, habitual en Castilla, consistente en su desglose en tres tercios: el llamado pontifical, para el obispo y cabildo catedralicio; otro tercio para los clérigos beneficiados de cada parroquia; y el restante para la fábrica de los templos parroquiales. De este último tercio, desde mediados del siglo XIII, se tomarían a su vez dos terceras partes con destino a las tercias reales, y de ahí la difícil situación económica que tuvieron que afrontar las fábricas parroquiales.

No obstante, en el caso de Cuenca se observa una peculiaridad con respecto a esta tónica general, consistente en que, ya desde fechas muy tempranas, se procedió a la división territorial de la diócesis en sectores dependientes fiscalmente del cabildo catedralicio o del obispo, lo cual ya quedaría semiesbozado en las donaciones de rentas a favor del cabildo realizadas a fines del siglo XII por el primer obispo conquense, don Juan Yáñez, evolucionando posteriormente hasta acabar configurándose la división de la diócesis en diversos sectores fiscales de participación capitular o

\footnotetext{
${ }^{50}$ Esta cuestión la trato mucho más ampliamente en mi artículo Pobreza y marginación en la Castilla bajomedieval. Notas sobre el ejercicio de la caridad en Cuenca a fines de la Edad Media, "Anuario de Estudios Medievales", 24 (1994), pp. 887-924.
} 
episcopal, en los cuales, por supuesto, también percibían sus correspondientes derechos los clérigos beneficiados y las fábricas parroquiales.

Así, al cabildo catedralicio correspondían préstamos y prestameras decimales en las tierras de Cuenca y Moya, más el ámbito manchego de Alarcón, el cual se dividía en tres cuadrillas encabezadas por Belmonte, Castillo de Garcimuñoz y la propia villa de Alarcón. La fábrica catedralicia, en cambio, percibió una pequeña porción decimal de trigo en cada una de las parroquias de todo el territorio diocesano.

Por su parte, la mesa episcopal percibía diezmos en los arciprestazgos de Requena, Uclés —donde, además de la Orden de Santiago, también recibía cierta porción decimal el cabildo catedralicio-, el sector de Iniesta con sus aldeas, todo el arcedianato de Huete y aquellos lugares que estaban sometidos al señorío del obispo: Pareja, Casasana, Paracuellos, Monteagudo, y las aldeas de la Obispalía en torno a Huerta, además de retener también algunos derechos decimales en la ciudad y arcedianato de Cuenca y, en menor medida, en el arcedianato de Alarcón. Estos sectores donde el obispo percibió diezmos se organizaban por mayordomías.

$\mathrm{Si}$, por lo general, el diezmo se dividió en tres tercios para el obispo o cabildo, clero beneficiado y fábrica parroquial (de la que luego se tomaban las tercias reales), también es cierto que fueron muchas las excepciones a esta regla, pues para algunos productos las proporciones variaron, existiendo en muchos lugares criterios específicos de reparto basados en la costumbre local.

En cuanto a la recaudación del diezmo, la parroquia constituyó la unidad fundamental para su cobro anual. En la diócesis de Cuenca, al igual que en otros lugares, hubo dos sistemas básicos de recaudación del diezmo. Por un lado su cobro directo a través de los aquí llamados terceros, cargo que solía recaer en clérigos y, a veces, en algunos laicos. El otro mecanismo de recaudación se basó en el arrendamiento anual de las rentas decimales en almoneda pública y bajo múltiples condiciones, actuando como arrendatarios tanto clérigos como laicos. Se trató de un sistema que fue habitualmente utilizado, al menos desde el siglo XIV, por las grandes instituciones eclesiásticas, sobre todo obispo y cabildo catedralicio, requiriendo de una infraestructura y normativa extremadamente complejas. 


\section{LAS RELACIONES DE PODER}

Es dentro de todo este marco institucional donde deben analizarse las relaciones de poder mantenidas por la Iglesia conquense, destacando en primer lugar las relaciones con la Monarquía castellana.

\section{Relaciones con la Monarquía castellana ${ }^{51}$}

El conjunto de la Baja Edad Media hispánica constituye una época de importancia fundamental en la configuración de unas relaciones IglesiaMonarquía cuyas características esenciales habrían de estar presentes durante todo el Antiguo Régimen. Por un lado, se fue produciendo un paulatino y lento proceso de estatalización de la Iglesia, en el sentido de que la Iglesia de cada reino irá quedando bajo el control de la Monarquía a través de cauces institucionales cada vez más definidos. Pero, por otra parte, y como contrapartida a lo anterior, también se produjo una eclesiastización del Estado, configurándose de este modo una permanente presencia de la Iglesia en los principales órganos de decisión política del reino. Este proceso de interpenetración Iglesia-Estado, que en el caso castellano se agudizó mucho a partir de la época Trastámara, jugará a favor del afianzamiento de la soberanía real, por lo que las relaciones Iglesia-Estado durante los siglos bajomedievales deben ser consideradas como un aspecto básico del triunfo de la soberanía regia a fines de la Edad Media, desempeñando un papel esencial dentro del proceso de génesis bajomedieval del Estado Moderno.

Estas relaciones de la Iglesia con la Monarquía se plasmaron en diversos ámbitos de la realidad, pudiendo distinguirse de este modo varios planos de realización: social, jurídico, eclesiástico, político y económico, planos todos ellos que, en el fondo, vienen a estar plenamente interrelacionados.

Centrándonos en el caso conquense y dentro del amplio periodo que abarca desde la fundación de la diócesis hasta el advenimiento de los Trastámara, cabe señalar en primer lugar que durante esta época más de la mitad de los prelados que ocuparon la mitra de Cuenca procedían de familias

\footnotetext{
${ }^{51}$ Sobre las relaciones Iglesia-Monarquía en Castilla durante la Baja Edad Media cabe destacar los trabajos del profesor J.M. NIETO SORIA. en particular sus libros Iglesia y poder real en Castilla. El Episcopado, 1250-1350, Madrid, 1988, e Iglesia y génesis del Estado Moderno en Castilla, 1369-1480. Madrid. 1993.
} 
vinculadas a la Realeza a través de la prestación de diversos servicios, concentrándose casi todos ellos en los siglos XII y XIII, durante los cuales algunos importantes linajes de mozárabes toledanos, como por ejemplo los Ruiz, Gudiel o Palomeque, tuvieron representantes al frente de la sede conquense ${ }^{52}$.

Desde un punto de vista jurídico, si bien no podemos afirmar con absoluta certeza la existencia sistemática de una forma de homenaje reyobispos conquenses, al margen de los homenajes recognoscitivos de carácter general, no se puede obviar, sin embargo, la valoración del modelo feudovasallático como horizonte interpretativo del modo en que se condujeron aspectos relevantes de las relaciones reyes-obispos.

Centrándonos en el plano eclesiástico, hay que destacar en primer lugar que durante este periodo resulta evidente la intromisión mayor o menor, según los casos, de la Monarquía castellana en el nombramiento de al menos la mitad de los obispos conquenses, incluso en aquellos casos en que la elección fue llevada a cabo teóricamente por el cabildo catedralicio. También durante esta época, sobre todo a partir de la primera mitad del siglo XIV, comenzaría a ponerse de manifiesto el interés de los monarcas por promover la provisión de beneficios en la Iglesia conquense en favor de algunos clérigos reales, si bien este proceso sólo adquirirá pleno vigor a partir del Cisma.

En un plano político, ya desde la primera mitad del siglo XIII comenzaremos a encontrar a algunos obispos conquenses desempeñando actividades o cargos políticos, y también militares, al servicio de la Realeza, siendo ello casi siempre consecuencia de la relación personal que determinados prelados mantuvieron con los monarcas castellanos. Hay que destacar el hecho de que la mayor parte de los prelados conquenses que durante este periodo intervinieron de forma relevante en política se sitúan en el siglo XIII, pudiendo citarse en concreto a don Gonzalo Juanes, don Mateo Reinal, don Pedro Lorenzo, don Gonzalo García Gudiel y don Gonzalo Díaz Palomeque. Ya para el siglo XIV, y hasta el advenimiento de la dinastía Trastámara, sólo tenemos plena constancia del desempeño de actividades políticas, y en concreto diplomáticas, por parte de un obispo conquense, don Juan del Campo.

\footnotetext{
${ }^{52}$ Estos prelados son en concreto García Ruiz (1208-1224), Lope Ruiz (1225-?), Gonzalo Ibáñez Palomeque (?-1247), Gonzalo Pérez Gudiel (1273-1275), Gonzalo García Gudiel (12801288) y Gonzalo Díaz Palomeque (1289-1299).
} 
En cuanto a la participación en Cortes de los prelados conquenses de este periodo $\mathrm{o}^{53}$, puede señalarse la asistencia en alguna ocasión por parte de los obispos don Juan Yáñez, don Mateo Reinal, don Rodrigo Juanes, don Pedro Lorenzo - que participó en varias reuniones de este tipo-, y don Pascual $^{54}$. Resulta interesante observar que también es en el siglo XIII donde se concentran la mayoría de los prelados que durante este periodo participaron en Cortes, al igual que sucede con los obispos que intervinieron en otras actividades políticas o militares, radicando sin duda la causa de ello en el hecho de que casi todos los prelados conquenses de esta centuria procedían de familias que tradicionalmente venían prestando servicios a la Monarquía, tendencia que se verá parcialmente interrumpida durante gran parte del siglo XIV.

Particular atención merece la participación de la ciudad e Iglesia conquense en los conflictos políticos del reinado de Pedro I, durante los cuales el obispo y cabildo catedralicio, apoyándose en la familia de los Albornoz, se enfrentarían al menos en determinadas ocasiones al citado monarca, lo que les llevó finalmente a mostrarse partidarios de Enrique II durante la guerra civil castellana de $1366-1369^{55}$. No obstante, a pesar de estos sucesos, a nivel institucional durante el reinado de Pedro I no hubo cambios notables en las relaciones Iglesia conquense-Monarquía castellana con respecto a las tendencias de épocas anteriores, y de hecho este monarca otorgaría a la Iglesia de Cuenca la correspondiente confirmación general de todos sus privilegios, llegándole a exigir también algunas contribuciones económicas en el transcurso de la guerra civil.

En el plano económico, la primera manifestación clara de proteccionismo monárquico hacia la economía de la Iglesia conquense vino dada por el propio proceso de dotación regia de la nueva diócesis, que corrió fundamentalmente a cargo de Alfonso VIII. Posteriormente, sobre todo tras

\footnotetext{
${ }^{53} \mathrm{La}$ participación del alto clero en Cortes, de forma general para toda la Corona de Castilla, ha sido objeto de un extenso estudio en forma de Tesis Doctoral realizado por A. ARRANZ GuZMÁn, Cortes medievales castellano-leonesas. Participación eclesiástica y mentalidades religiosas. Tesis Doctoral presentada en la Universidad de Alcalá de Henares en 1988. Un resumen de dicho trabajo puede verse en: A. ARRANZ GUZMÁN, Reconstrucción y verificación de las Cortes castellano-leonesas: la participación del clero, "En la España Medieval", 13 (1990), pp. 33-132.

${ }^{54}$ Son datos tomados de la obra antes citada.

${ }^{55}$ Ya en 1366 Enrique II confirmaría algunos privilegios al obispo y cabildo catedralicio conquense. ACC, siglo XIV, $n^{\circ} 275$.
} 
el reinado de Alfonso X, las nuevas donaciones reales en favor de la Iglesia de Cuenca serían escasísimas.

Pero, aparte de las donaciones de bienes, este proteccionismo regio en el ámbito económico también tuvo otra importante y más continua manifestación en el otorgamiento a la Iglesia conquense de privilegios diversos de contenido económico y sobre todo en la confirmación general de los ya existentes, sucediendo esto último fundamentalmente en aquellos momentos de mayor relieve político de cada reinado. Por otro lado, la Monarquía también concedería una amplia protección al cabildo catedralicio en los conflictos que éste tuvo con los concejos de la diócesis, sobre todo el de la ciudad de Cuenca.

El proteccionismo regio en materia económica tuvo otro ámbito de plasmación en las frecuentes intervenciones de los monarcas destinadas a propiciar un más correcto pago del diezmo en el obispado, concentrándose dichas actuaciones regias fundamentalmente en la segunda mitad del siglo XIII y primera de la centuria siguiente, en una época de conflictividad generalizada en toda Castilla en torno a la percepción de este importante tributo eclesiástico. Se trató, además, de una protección interesada, en el sentido de que los monarcas sabían que cuanto mejor se pagara el diezmo a la Iglesia más puntualmente podrían ellos percibir la parte de dicho diezmo que les correpondía a través de las tercias reales.

Pero, como contrapartida de este proteccionismo, las rentas de la Iglesia conquense también fueron objeto de una constante fiscalización por parte de la Monarquía castellana, manifestándose dicha físcalización en el consabido pago de tercias reales, décimas, cruzadas y algunos servicios extraordinarios para sufragar las empresas militares de los monarcas, lo que no pocas veces motivó airadas quejas por parte de la clerecía diocesana conquense contra el pago de unos tributos que se consideraban excesivos.

Las relaciones económicas de la Monarquía castellana con la Iglesia conquense también tuvieron una dimensión conflictiva que quedaría reflejada, por un lado, en el constante y paulatino incremento que, a pesar de las protestas concejiles, experimentaron en el obispado los territorios de abadengo a costa del realengo ${ }^{56} \mathrm{y}$, por otro, en algunos intentos por parte

${ }^{56}$ Sobre esta cuestión, y para el conjunto de la Corona de Castilla, puede verse el trabajo de J.M. NiETo SoriA, Abadengo episcopal y realengo en tiempos de Alfonso XI de Castilla, "En la España Medieval. IV. Estudios dedicados al profesor don Ángel Ferrari Núñez", vol. II, Madrid, 1984, pp. 707-734, así como el de A. ARRANZ GUZMÁN, El tercer estado castellano 
del rey o sus recaudadores de exigir indebidamente al cabildo catedralicio el pago de algunos tributos que en realidad no le correspondía entregar, como sucedió con el yantar.

Centrándonos a continuación en el periodo Trastámara, conviene señalar primeramente que durante esta época, y a nivel general para toda Castilla, se desarrolló un complejo proceso de institucionalización de los resultados obtenidos en las etapas anteriores en lo que respecta a las relaciones Iglesia-Monarquía. De este modo, con los Trastámara la interpenetración Realeza-Iglesia habría de ser significativamente mayor que en el periodo precedente, lo que, sin duda, constituyó un factor fundamental en la evolución del proceso de génesis bajomedieval del Estado Moderno en Castilla.

Durante la época Trastámara, al igual que sucedió en la etapa anterior, bastantes de los prelados que ocuparon la sede conquense, aunque no todos, procedieron de familias de la mediana nobleza castellana en mayor o menor medida vinculadas a la Monarquía a través de la prestación de diferentes servicios ${ }^{57}$, siendo éste un factor que sin duda facilitó el ascenso de estos personajes en la carrera eclesiástica gracias a la mediación regia.

En el plano eclesiástico, debe señalarse primeramente que en este periodo, salvo alguna excepción, acabaría por imponerse definitivamente la provisión pontificia previa súplica regia como el sistema habitual de designación de los obispos de Cuenca, no faltando algunos sonados enfrentamientos de la Monarquía con la Santa Sede en torno a la elección de determinados prelados conquenses, tal como sucedió en el caso de la provisión del cardenal Antonio Jacobo de Veneris realizada por Paulo II en 1469 a instancias del propio cardenal y del marqués de Villena ${ }^{58}$, provisión a la que se opondrían el concejo y cabildo catedralicio conquense y el rey Enrique IV, a pesar de lo cual acabó triunfando el candidato pontificio. Todavía más importante y prolongado en el tiempo fue el conflicto que se originó en 1479, tras la muerte del cardenal Veneris, entre los Reyes

ante las relaciones realengo-abadengo. Siglos XIII-XV, "Hispania", XLIX/172 (1989), pp. 443 476.

${ }^{57} \mathrm{Tal}$ fue el caso de Pedro Alfonso de Toledo (1373-1378), Nicolás Fernández de Biedma (1378-1381), Juan Fernández Cabeza de Vaca (1396-1407), Diego de Anaya Maldonado (14071418), Álvaro Núñez de Isorna (1418-1445), Fray Lope de Barrientos (1445-1469) y Fray Alonso de Burgos (1482-1485).

${ }^{58}$ ASVat., Reg. Lat. 700, ff. 50r-52r. 
Católicos y Sixto IV por la provisión de la sede de Cuenca, imponiéndose finalmente en 1482, tras tres años de largas negociaciones, el candidato regio, Fray Alonso de Burgos ${ }^{59}$.

Pero, además, en la época Trastámara, y de manera particularmente acusada durante el Cisma, también se intensificó extraordinariamente la suplicación de beneficios por parte de los monarcas solicitando al papa determinadas concesiones beneficiales en la Iglesia y diócesis de Cuenca en favor de numerosos clérigos, siendo éste un fenómeno que también se observa para el resto de las diócesis y que constituye una típica manifestación del intervencionismo regio en la configuración personal de la Iglesia del reino, puesto que, por esta vía, se garantizaba la presencia de los que se podrían denominar como clérigos del rey, que se encontraban distribuídos por toda la geografía del reino y a lo largo de toda la jerarquía eclesiástica.

Asimismo, hay que destacar que durante el periodo Trastámara aumentó la presencia de algunos capellanes reales - personajes de relieve tanto eclesiástico como político- ocupando beneficios en la Iglesia conquense, fundamentalmente en el cabildo catedralicio y en la parroquia de Santa María y monasterios de Santa Clara y San Miguel del Monte de la villa de Alcocer, donde Enrique III había fundado siete capellanías perpetuas $^{60}$.

Desde fines del siglo XIV, y sobre todo a lo largo de la centuria siguiente, también se intensificaría extraordinariamente, en todos los órdenes, la participación de los obispos y a veces algunos eclesiásticos de Cuenca en la cada vez más compleja vida política del momento. Por un lado, mediante el desempeño por los obispos de cargos políticos de relieve, tales como consejero real, canciller mayor, preceptor del príncipe, oidor de la Audiencia real, confesor y capellán regio. Por otra parte, a través de la asistencia de algunos prelados a Cortes, tal como sucedió con don Álvaro Martínez, don Juan Cabeza de Vaca, don Álvaro de Isorna y Fray Lope de Barrientos, todos los cuales también participaban activamente en política.

Esta dimensión política del Episcopado conquense también se manifestaría de forma muy acusada a través de la participación relevante de algunos prelados en importantes conflictos políticos tanto nacionales como

\footnotetext{
${ }^{59}$ Este sonado conflicto entre los Reyes Católicos y Sixto IV por la provisión de la sede conquense ha sido analizado con detalle por T. DE AZCONA, La elección y reforma del Episcopado español en tiempo de los Reyes Católicos, Madrid, 1960, pp. 109-136.

${ }^{60}$ AGS, Registro General del Sello, 15-V-1492, f. 391.
} 
internacionales. Por un lado debe destacarse la defensa armada de la ciudad de Cuenca que, al frente de las tropas concejiles, y por mandato de Juan II, hizo en 1447 y 1449 el obispo Barrientos contra el noble don Diego Hurtado de Mendoza y sus partidarios ${ }^{61}$; ya hacia el final de su pontificado, en 1464 y 1465 , este mismo prelado actuaría en Cuenca y su diócesis como dirigente del movimiento de defensa de la causa de Enrique IV durante los levantamientos proalfonsinos ${ }^{62}$. En el ámbito internacional hay que poner de relieve la participación de algunos obispos y eclesiásticos conquenses en actividades diplomáticas durante el Cisma y años posteriores, descollando en importancia el destacado papel que en las embajadas castellanas enviadas al Concilio de Constanza ${ }^{63}$ y al Concilio de Basilea $^{64}$ ejercerían, respectivamente, los obispos don Diego de Anaya y don Álvaro de Isorna.

La protección de los monarcas Trastámara hacia la economía de la Iglesia conquense se canalizó fundamentalmente a través del otorgamiento de confirmaciones generales de privilegios, siendo muy limitadas las nuevas concesiones. Por otro lado, durante esta época la Monarquía prestaría con frecuencia protección al cabildo catedralicio en sus conflictos económicos con los concejos y la Orden de Santiago.

En el ámbito de la fiscalidad regia sobre la Iglesia, en este periodo la tipología de los tributos apenas aportó novedades con respecto a etapas anteriores, siendo las tercias, décimas, subsidios y cruzadas sus manifestaciones más habituales, si bien ahora tendría lugar la conversión en exacciones ordinarias, en unos casos, o frecuentes, en otros, de las que en épocas anteriores habían sido extraordinarias o infrecuentes. No faltaron las situaciones en que el conjunto del clero conquense expresó sus quejas contra la fuerte presión fiscal de la Monarquía, que se agudizaría desde comienzos de los años ochenta del siglo XV con motivo de la guerra de Granada.

Finalmente, en lo tocante a la dimensión conflictiva que a veces adquirieron las relaciones económicas de la Monarquía Trastámara con la Iglesia conquense, cabe señalar que también ahora, al igual que había

\footnotetext{
(1)P. Carrillo DE Huete, Crónica de Juan II, edic. de Juan de Mata Carriazo, Madrid, 1946 , pp. $482-487$ y $513-516$.

${ }^{62}$ Archivo Municipal de Cuenca (AMC), leg. 197, exp. 3, ff. 20r-22v.

${ }^{63}$ Sobre ello puede verse: J. GoÑ GAZTAMBIDE, Los españoles en el Concilio de Constanza. Notas biográficas, Madrid, 1966.

${ }^{6}$ En este punto cabe destacar el trabajo de V. BELTRAN DE HEREDIA, La embajada de Castilla en el Concilio de Basilea, "Hispania Sacra", X (1957), pp. 5-32.
} 
sucedido en épocas anteriores, tuvo un claro ámbito de manifestación en el incremento de los abadengos a costa de las tierras de realengo, así como en la confiscación ocasional, ya muy a fines de la Edad Media, de algunos bienes eclesiásticos por parte de la Inquisición.

\section{Relaciones intraeclesiales}

La enorme jerarquización interna que, tanto a nivel eclesiástico como socioeconómico, se daba en el seno de la propia Iglesia hizo inevitable el establecimiento de unas relaciones de poder entre los integrantes del estamento eclesiástico. En este sentido, con frecuencia la documentación deja entrever situaciones conflictivas en el desarrollo de algunas de estas relaciones intraeclesiales, siendo más o menos abundantes e intensos los conflictos según los momentos y características concretas de cada caso, pero también hay que tener en cuenta que los documentos tienden sobre todo a resaltar el elemento contencioso, no quedando recogidas muchas y abundantes situaciones en que las relaciones se desenvolvieron con normalidad y sin conflictos.

Las relaciones de la Iglesia de Cuenca con el Papado ${ }^{65}$ tuvieron uno de sus más importantes ámbitos de plasmación en la política beneficial, destacando dentro de esta última en primer lugar los nombramientos episcopales. Ya durante el siglo XIII tuvieron lugar algunas provisiones episcopales de la sede conquense realizadas por el papa. Sin embargo, fue a partir del siglo XIV cuando la provisión por el pontífice se convirtió en el sistema habitual de nombramiento de los obispos de Cuenca. En total son 21 las provisiones pontificias de que tenemos noticia para la época medieval ${ }^{66}$.

Ahora bien, debe tenerse en cuenta que muchas de estas provisiones las realizó el papa en atención a una súplica previa del monarca castellano. En algunas provisiones, sin embargo, pudieron influir tanto los deseos del rey como los del propio pontífice, mientras que sólo en contadas ocasiones la provisión fue realizada por clara iniciativa del papa y como respuesta sobre todo a los deseos de éste.

\footnotetext{
${ }^{10.5}$ Un análisis general de esta cuestión para el conjunto de la baja Edad Media aparece recogido en mi artículo Pontificado e iglesias locales en Castilla. El caso del obispado de Cuenca (siglos XII-XV), "Anthologica Annua", 44 (1997), pp. 381-483.

${ }^{\text {"N }}$ Sobre todas estas provisiones pontificias poseemos puntual información gracias a los registros vaticanos.
} 
Pero la política beneficial del Papado también se manifestó con respecto al resto de beneficios eclesiásticos, fundamentalmente los capitulares. Especial relieve tuvieron las legaciones pontificias de los cardenales Juan de Abbeville en 1229 y Gil de Torres en 1251, destinadas a racionalizar el reparto de beneficios en el cabildo catedralicio conquense y a establecer algunas condiciones para su percepción ${ }^{67}$. No obstante, ante todo deben ser destacadas las numerosas concesiones por el Papado de beneficios eclesiásticos en la ciudad y obispado conquense a favor de determinados clérigos.

Este proceso se inició ya en el siglo XIII, época en que tenemos algunas pocas noticias sobre otorgamiento por el papa de algunos beneficios en el cabildo catedralicio conquense a favor de algunos clérigos extranjeros. La centralización del periodo aviñonés supondría una intensificación de esta tendencia, sobre todo con Juan XXII, que confirió bastantes beneficios en el cabildo tanto a clérigos extranjeros como de origen hispano, continuando dicho proceso con los pontífices siguientes.

Pero donde, sin duda, adquirió mayor vigor este otorgamiento de beneficios fue en las numerosísimas concesiones beneficiales realizadas por el papa en atención a súplicas previas presentadas por determinados personajes o instituciones. Fue fundamentalmente durante los siglos XIV y $\mathrm{XV}$ cuando más abundaron estas suplicaciones ante los pontífices solicitando la concesión de beneficios en la Iglesia de Cuenca a ciertos clérigos, descollando en importancia las súplicas de los monarcas castellanos, sobre todo durante el Cisma ${ }^{68}$, y las realizadas tiempo atrás por el cardenal Albornoz, cuyo influjo sobre la Iglesia conquense fue enorme ${ }^{69}$. El propio cardenal ostentó la dignidad de arcediano de Huete en el cabildo catedralicio de Cuenca, y durante los pontificados de Inocencio VI y Urbano V presentaría gran cantidad de súplicas ante el papa solicitando fundamentalmente la concesión de canonjías y dignidades en la catedral conquense a favor de sus parientes, familiares y protegidos.

\footnotetext{
${ }^{67}$ En este punto cabe destacar el trabajo de J.M. NIETO SORIA, El intervencionismo pontificio sobre la Iglesia conquense en el siglo XIII, "Hispania", XLV/159 (1985), pp. 33-58.

${ }^{67}$ ASVat., Reg. Suppl. no 63, ff. 50r-53r; no 62, ff. 19v-20r; n 95, f. 222r; n 100, ff. $216 \mathrm{r}-233 \mathrm{v}$. Se trata tan sólo de algunas referencias documentales de entre las muchas que podrían citarse concernientes a esta cuestión.

${ }^{69}$ Muchas de estas súplicas presentadas por el cardenal Albornoz aparecen recogidas en: E. SÁEZ ET ALII, Diplomatario del cardenal Gil de Albornoz. Cancillería pontificia, Barcelona, CSIC, 1976-1995, 3 vols.
} 
Pero, además de estas súplicas regias y del cardenal Albornoz, y sin adquirir tanto relieve, desde la primera mitad del siglo XIV y especialmente durante el Cisma también se produjeron algunas suplicaciones de beneficios, sobre todo en el cabildo catedralicio conquense, presentadas ante el papa por otros cardenales, algunos obispos de Cuenca u otras diócesis, ciertos nobles castellanos y algunos centros universitarios, destacando en este último punto las súplicas presentadas por la Universidad de Salamanca en favor de clérigos estudiantes ${ }^{70}$.

La fiscalidad pontificia fue otro importante ámbito de manifestación de las relaciones con el Papado. En primer lugar, habría que destacar el pago de servicios comunes y menudos a la Cámara Apostólica y oficiales de la Curia que estaban obligados a realizar los prelados al acceder a la mitra. En el caso conquense, la cantidad a entregar en concepto de servicios comunes quedaría establecida en 500 florines de oro a partir del año 1300, con el obispo don Pascual, que es cuando tenemos la primera noticia sobre el pago de esta tributación ${ }^{71}$, manteniéndose inalterable hasta que en 1470 la Cámara Apostólica procediese a su actualización, estableciéndose que en adelante fuesen 3000 los florines de oro a pagar por este concepto ${ }^{72}$, lo que estaba mucho más acorde con el verdadero nivel de rentas que la mitra conquense tenía por entonces.

Pero, además de este obligado pago de servicios comunes y menudos por los obispos, la presión fiscal pontificia sobre la Iglesia conquense también se manifestó muy frecuentemente a través de la imposición de diversas exacciones que adquirirían una mayor o menor importancia e intensidad según las épocas. Para el siglo XIII los datos que se nos han conservado sobre esta materia son francamente escasos, comenzando ya a abundar algo más la información a partir de la primera mitad del siglo XIV, que es precisamente cuando la presión fiscal del Papado comenzó a cobrar un mayor vigor en todo el Occidente cristiano. No obstante, las noticias que para los siglos XIV y XV se conservan sobre fiscalidad pontificia en lo referente a la diócesis conquense son incompletas y fragmentarias, de tal forma que son bastantes las aportaciones concretas realizadas por la Iglesia

\footnotetext{
${ }^{71} \mathrm{~V}$. BELTRÁN DE HEREDIA, Bulario de la Universidad de Salamanca (1219-1549), Salamanca, 1966, I, n"s 162, 220, 273, 278, 279, 341, 367.

${ }^{71}$ ASVat., Obligationes et Solutiones, vol. 1, f. $11 \mathrm{v}$.

${ }^{72}$ Ibídem, vol. 84, f. $110 \mathrm{r}$.
} 
de Cuenca sobre las que no nos ha quedado información, impidiendo ello el que pueda realizarse una adecuada valoración de conjunto sobre la presión fiscal del Papado en esta diócesis durante la Baja Edad Media.

Con todo, alguna apreciación sí que puede hacerse. Así, por ejemplo, hay que destacar la importancia cuantitativa de los subsidios contra el turco que se cobraron durante el siglo XV. Por otro lado, los datos que se conservan sobre el cobro de derechos de espolio también nos indican cifras de cierta consideración, mientras que las cantidades pagadas en concepto de procuraciones a ciertos legados suelen ser menores.

En definitiva, la Iglesia de Cuenca tuvo que hacer frente durante la Baja Edad Media a una fiscalidad pontificia más o menos intensa según los momentos, a lo que se venía a añadir la constante físcalización de que eran objeto las rentas eclesiásticas por parte de la Monarquía, explicándose de este modo los frecuentes retrasos y protestas en el pago de ciertas exacciones pontificias que se consideraban a todas luces abusivas.

Otro ámbito de intervención de la Santa Sede es el que vino dado por la mediación del papa en algunos conflictos que, en ocasiones, se produjeron con relación al mantenimiento de un cierto nivel disciplinario y moral en el Episcopado y clero de la diócesis, siendo el Papado ante estas cuestiones particularmente sensible. Son varios los ejemplos con que contamos sobre actuaciones en esta materia, pudiendo destacarse la intervención pontificia relativa a los enfrentamientos que entre 1217 y 1221 se produjeron entre el obispo don García Ruiz y algunos miembros del cabildo catedralicio ${ }^{73}$ y, sobre todo, la necesaria mediación del papa con respecto a algunos gravísimos y violentos incidentes protagonizados a mediados del siglo XIV por el obispo don García en sus señoríos de Pareja y Casasana ${ }^{74}$.

Un amplio terreno de manifestación del intervencionismo pontificio fue también el que estuvo constituído por todo un conjunto de actuaciones del Papado mediante las que se concedieron licencias y mercedes de carácter diverso, siempre de índole eclesiástica, a favor de algunos laicos y nobles del obispado conquense, así como indulgencias en favor de los fieles cristianos, produciéndose la mayor parte de estas intervenciones en los siglos XIV y XV. Por otro lado, en ocasiones el papa comisionaría a algunos obispos

\footnotetext{
${ }^{73}$ J.M. NieTo SoRIA, El intervencionismo pontificio, cit., pp. 48-51.

${ }^{74}$ Don García había mandado dar muerte a quince vasallos de su señorío de Casasana, y también se le acusaba de cometer adulterio, incesto y de tener concubinas. ASVat., Reg. Vat. 145, ff. $200 v-201 r$.
} 
conquenses para la realización de empresas diversas en nombre de la Santa Sede.

Finalmente, las relaciones de la Iglesia de Cuenca con el Papado también quedaron plasmadas en la participación del Episcopado conquense y otros miembros del clero catedralicio y diocesano en algunas de las más importantes asambleas conciliares de carácter general que se celebraron en el transcurso de los siglos bajomedievales. En concreto, fueron al menos tres los grandes concilios generales de la Iglesia que contaron con esta participación conquense: el IV Concilio de Letrán y, de manera especialmente destacada, el Concilio de Constanza y el Concilio de Basilea, asambleas todas ellas de gran trascendencia ${ }^{75}$.

En lo que atañe a las relaciones mantenidas con la metrópoli toledana, hay que señalar que a menudo estuvieron condicionadas por la situación de dependencia que Cuenca, como sufragánea de la Iglesia de Toledo, mantuvo con respecto a ésta. Dicha dependencia se manifestó de diversas formas, como fueron las cartas de obediencia que hasta comienzos del siglo XIV tuvieron que firmar los obispos de Cuenca al ir a ser consagrados, la asistencia de algunos obispos conquenses a los concilios provinciales toledanos, la condición de tribunal de apelación que tuvo la Iglesia toledana, el inevitable influjo de Toledo en materia litúrgica y sinodal y la más que probable intromisión de los arzobispos de Toledo, durante el siglo XIII, en algunas de las elecciones episcopales realizadas por el cabildo catedralicio conquense en favor de personajes nobles procedentes de familias de mozárabes toledanos muy vinculadas a la sede arzobispal.

Tampoco faltaron ocasionalmente algunos conflictos en las relaciones de los arzobispos de Toledo con los obispos de Cuenca, motivados fundamentalmente por abusos del metropolitano en materia económica. Así sucedió, por ejemplo, durante el pontificado de los obispos don García Ruiz, en el siglo XIII, y don Pascual, en la centuria siguiente, originándose sendos pleitos cuya resolución en ambos casos fue favorable al obispo conquense ${ }^{76}$.

\footnotetext{
${ }^{75}$ El IV Concilio de Letrán contó con la asistencia del obispo don García Ruiz, el Concilio de Constanza con la de don Diego de Anaya, y el Concilio de Basilea con la de don Álvaro de Isorna.

${ }^{76}$ Todo ello aparece recogido por extenso en mi artículo Las relaciones entre la Iglesia conquense y los arzobispos de Toledo durante la Edad Media, "Anales Toledanos", 33 (1996), pp. 23-32.
} 
En cuanto a las relaciones establecidas con algunas diócesis fronterizas con la de Cuenca, sólo de manera esporádica se produjeron conflictos por cuestión de límites. Tal fue el caso de las disputas que a fines del siglo XII hubo con la diócesis de Albarracín respecto a la localidad de Cañete, que finalmente pasaría a depender de la jurisdicción eclesiástica conquense, mientras que en 1322 se produjo un litigio con el obispo de Cartagena, que pretendió sin éxito arrebatar la parroquia de La Roda al obispado conquense ${ }^{77}$.

En el ámbito de las relaciones intraeclesiales mantenidas en el seno de la propia Iglesia de Cuenca, cabe destacar primeramente las del obispo con el cabildo catedralicio, las cuales, aunque a menudo se desenvolvieron en el marco de la mutua cooperación que teóricamente siempre debía existir, también a veces darían lugar a conflictos más o menos graves y prolongados en el tiempo según cada caso. Las motivaciones de estos conflictos fueron fundamentalmente de índole económica y jurisdiccional, pudiendo destacarse los que enfrentaron al cabildo catedralicio con los obispos don Pascual ${ }^{78}$, don Bernal Zafón ${ }^{79}$, don Antonio Jacobo de Veneris y su provisor Gabriel Condulmario $^{80}$, Fray Alfonso de Fonseca ${ }^{81}$ y, de manera especialmente intensa, con don Pedro de Costa, provisor del cardenal de San Jorge ${ }^{82}$, continuando aún los enfrentamientos en época del obispo don Diego Ramírez de Villaescusa, ya entrado el siglo $\mathrm{XVI}^{83}$.

Todos estos conflictos entre el obispo y el cabildo catedralicio, en definitiva, deben ser interpretados como el resultado de la frecuente contraposición de intereses que a menudo se producía entre las dos élites de máximo poder eclesiástico del obispado de Cuenca, élites de poder que, aunque en muchísimos aspectos se compenetraban mutuamente, no por ello cesaban en la pretensión de defender y ampliar sus respectivas competencias y derechos.

\footnotetext{
${ }^{77} \mathrm{ACC}$, siglo XIV, $\mathrm{n}^{\circ} 281$.

${ }^{78} \mathrm{ACC}$, caj. 8, leg. 34, no 682.

${ }^{79} \mathrm{ACC}$, siglo XIV, $\mathrm{n}^{\circ} 262$.

${ }^{\text {"I }}$ AGS, Registro General del Sello, 15-I-1479, f. 6.

${ }^{81}$ ACC, caj. 7, leg. 38, n⿳0 781.

${ }^{82} \mathrm{ACC}$, caj. 9, leg. 38, $\mathrm{n}^{\mathrm{0}} 766$ bis.

${ }^{83} \mathrm{ACC}$, caj. 7, leg. 38, no 781.
} 
Las disputas que a veces se produjeron entre el cabildo catedralicio y algunos de sus integrantes casi siempre fueron de carácter económico, girando sobre todo en torno a la obligatoriedad de residencia para poder percibir el beneficio capitular. En este sentido, cabe destacar los conflictos que desde el siglo XIV se desencadenaron entre el cabildo y algunos canónigos que, alegando estar estudiando en las Universidades, pretendían cobrar su renta beneficial a pesar de no residir en Cuenca, quejándose el cabildo de los abusos que a veces se producían al respecto.

En cuanto a las relaciones del obispo con el clero diocesano, en el ámbito económico tendrían su manifestación a través de los principales derechos que el clero estaba obligado a satisfacer al prelado: el catedrático, cuya entrega fue siempre obligatoria; la luctuosa, cuyo pago pronto se reservaría sólo a ciertos clérigos; las procuraciones de visita, que a veces originaron pequeños conflictos; y algunos servicios episcopales que ocasionalmente se imponían para costear determinados gastos.

Por otro lado, el cabildo catedralicio siempre gozaría de algunos privilegios económicos y jurisdiccionales que no poseía el clero diocesano, contribuyendo ello a afianzar su posición de supremacía eclesiástica junto al obispo. Fue precisamente ésto lo que a veces dio lugar a algunos conflictos entre el cabildo catedralicio y la clerecía de Cuenca y su obispado, como los acaecidos en época de San Julián ${ }^{84}$ y don Álvaro de Isorna ${ }^{85}$.

Respecto a las relaciones del obispo y cabildo catedralicio con los dos principales colectivos clericales que había en la diócesis, los cabildos de clérigos beneficiados de Cuenca y Huete, tenemos información sobre todo referente a este último ${ }^{86}$, debiendo destacarse la amplia protección y privilegios que el obispo y cabildo catedralicio siempre otorgaron a los clérigos beneficiados del cabildo optense, contribuyendo de este modo a afianzar la situación de superioridad económica y jurisdiccional del clero urbano de Huete con respecto al clero de las aldeas de su Tierra.

En el seno del clero diocesano parroquial también se produjeron con frecuencia, ya desde el siglo XIII, algunos conflictos fundamentalmente en torno al cobro del diezmo. En este sentido, los conflictos decimales más

\footnotetext{
${ }^{84} \mathrm{ACC}$, caj. 2, $\mathrm{n}^{\circ} 34$.

${ }^{85} \mathrm{ACC}$, caj. 8, leg. 34, no 694.

${ }^{86} \mathrm{La}$ mayor parte de documentación referente al cabildo de clérigos beneficiados de Huete se encuentra actualmente en el Archivo Histórico Provincial de Cuenca.
} 
característicos entre los diversos clérigos parroquiales fueron los referentes al modo de reparto del diezmo de aquellas personas que labraban tierras situadas en el ámbito jurisdiccional de diferentes parroquias, abundando también los conflictos sobre el diezmo del ganado, de gran importancia en tierras conquenses ${ }^{87}$.

En cuanto a las relaciones entre el obispo y cabildo catedralicio y algunos monasterios de religiosos, las mejor conocidas son, con diferencia, las mantenidas con la abadía cisterciense de Monsalud. Tras los acuerdos iniciales del año 1193 a través de los cuales se determinó la exención del pago de diezmos de que gozaría el monasterio ${ }^{88}$, en adelante las relaciones entre Monsalud y el obispo y cabildo catedralicio conquense se desarrollarían sin apenas conflictos, gozando además el monasterio de un importante grado de autonomía con respecto a la autoridad episcopal. No obstante, en última instancia Monsalud siempre hubo de reconocer la posición supremacía eclesiástica ostentada por el obispo y cabildo, lo que quedaría reflejado en una pequeña ofrenda simbólica de dinero que todos los años se tenía que hacer en el altar de la catedral conquense.

Las relaciones mantenidas por el obispo y cabildo con los demás monasterios de religiosos de la diócesis apenas las conocemos, dada la gran escasez de datos al respecto. No obstante, hay que destacar el empeño que, sobre todo a fines de la Edad Media, pusieron algunos obispos de Cuenca para que todas las Órdenes religiosas que no tuvieran privilegios de exención decimal pagasen puntualmente sus diezmos correspondientes.

Un último tipo de relaciones de orden intraeclesial es el que vino dado por las mantenidas con aquellas Órdenes militares que tenían propiedades dentro del territorio diocesano conquense ${ }^{89}$, descollando en importancia desde un primer momento las relaciones con la Orden de Santiago, dado que en torno a Uclés existía una de las encomiendas santiaguistas más importantes de toda la Península Ibérica, hallándose inmersa en gran parte dentro del ámbito jurisdiccional de la diócesis de Cuenca. Además, en el territorio de

\footnotetext{
${ }^{87}$ De todos estos conflictos decimales nos dan detallada noticia los sínodos diocesanos conquenses, en los que se recogen constantes disposiciones para tratar de resolver este tipo de enfrentamientos entre parroquias.

${ }^{8 x}$ M. LóPEZ, Memorias históricas de Cuenca y su obispado, Madrid, 1953, II, pp. 145-146.

${ }^{89}$ Ésta es una cuestión que la trato detalladamente en mi artículo Las Órdenes militares y la Iglesia de Cuenca durante la Edad Media, "Actas del Congreso internacional sobre las Órdenes militares en la Península Ibérica" (Ciudad Real-Almagro, 6 al 9 de mayo de 1996), en prensa.
} 
la encomienda de Uclés la Orden fundaría un buen número de iglesias que quedarían bajo su patronato. Esto implicó el mantenimiento de unas muy estrechas relaciones con la Iglesia de Cuenca durante toda la época bajomedieval y también en siglos posteriores. De este modo, ya desde fines del siglo XII y muy poco después de tener lugar la fundación de la diócesis, el obispo y cabildo catedralicio conquense comenzarían a realizar los primeros acuerdos con la Orden de Santiago tanto en materia económica -sobre todo derechos decimales- como jurisdiccional, lo que no evitó que, junto a momentos de pacífica convivencia, también surgiesen frecuentes conflictos que, con mayor o menor intensidad según las épocas, se sucederían a lo largo de los siglos bajomedievales. Junto a los conflictos jurisdiccionales, los económicos fueron los más frecuentes, estando motivados fundamentalmente por los impedimentos que los santiaguistas pusieron a la saca de las rentas decimales correspondientes al cabildo catedralicio en los lugares de la encomienda de Uclés.

Otras Órdenes militares que también poseyeron algunos pocos bienes dentro del ámbito diocesano conquense fueron las de Calatrava, San Juan de Jerusalén, Temple y Santa María de Cartagena, si bien la importancia de las propiedades que tenían en el obispado era mínima. Las relaciones que el obispo y cabildo catedralicio establecieron con estas Órdenes militares en general fueron muy poco intensas, conociéndose algún que otro esporádico conflicto sobre todo de carácter decimal. No obstante, hay que destacar que la abadía cisterciense de Monsalud, situada al norte de la diócesis y cerca de una zona donde los calatravos poseían abundantes dominios, sí que mantendría una vinculación mucho más estrecha con esta última Orden militar.

\section{Relaciones con la sociedad local}

En el ámbito de las relaciones entre la Iglesia conquense y la sociedad local, en primer lugar hay que hacer referencia a las mantenidas con el concejo de Cuenca y otros concejos del obispado. Estas relaciones, aunque no siempre, sí muy frecuentemente se desarrollaron con un fuerte componente de conflictividad, al tratarse de dos poderes que se limitaban mutuamente en su afán expansivo, siendo por ello muchas veces necesaria la mediación regia para tratar de resolver, a menudo sin éxito, las disputas de índole tanto económica como jurisdiccional surgidas entre las potestades 
eclesiástica y concejil ${ }^{90}$. Por otro lado, es necesario poner de manifiesto que a menudo estas relaciones tuvieron también un importante componente de relaciones Iglesia-nobleza, en cuanto que una buena parte de la potestad concejil era ejercida por algunas importantes familias de la nobleza conquense.

Muchos de los conflictos que enfrentaron a la Iglesia de Cuenca, sobre todo el cabildo catedralicio, con el concejo conquense y con otros concejos de la diócesis tuvieron motivaciones de carácter económico. En el caso de los conflictos económicos con el concejo de Cuenca, éstos comenzarían a ser más frecuentes sobre todo desde mediados del siglo XIII, estando motivados muchas veces por la lógica reacción concejil contra los abundantes privilegios de que disponían el obispo y cabildo catedralicio. Tras un importante clímax de este tipo de conflictos durante el primer cuarto del siglo $\mathrm{XV}$, poco a poco los enfrentamientos se irían reduciendo, viéndose sin duda ello favorecido por la estrecha colaboración sin precedentes que se dio entre el obispo Barrientos y el concejo conquense, a pesar de lo cual aún continuaron produciéndose algunos esporádicos enfrentamientos durante el resto de la centuria.

Aunque en menor medida que en el caso anterior, también se produjeron, ya desde el siglo XIII, algunos enfrentamientos por razones económicas diversas entre el cabildo catedralicio y otros concejos de la diócesis, siendo especialmente frecuentes los conflictos con el concejo de Moya y los arrendadores de las salinas de Fuente el Manzano, motivados por la negativa de éstos a entregar al cabildo la sal que todos los años le correspondía en dichas salinas por privilegio real, así como por la permisividad que con respecto a ello a menudo mostraba el concejo de Moya.

La otra parte de los conflictos que enfrentaron a la Iglesia conquense con los concejos del obispado, especialmente el de Cuenca, tuvo motivaciones de carácter jurisdiccional, surgiendo desde fechas muy tempranas frecuentes conflictos entre las jurisdicciones concejil y eclesiástica a la hora de establecer cuál de ellas debía encargarse de juzgar a determinados individuos cuando cometían ciertos delitos, conflictos que, con mayor o menor intensidad, se sucederían a lo largo de todo el periodo bajomedieval, y ello a pesar de los acuerdos y compromisos tomados al respecto a comienzos del

\footnotetext{
${ }^{\text {"N }}$ Sobre ello puede verse mi artículo Monarquia y conflictos Iglesia-concejos en la Castilla bajomedieval. El caso del obispado de Cuenca (1280-1406), "En la España Medieval", 17 (1994), pp. 133-156.
} 
siglo XIII. De este modo, las disputas surgieron tanto cuando la jurisdicción concejil se inmiscuyó en la eclesiástica como cuando fue esta última la que se entrometió indebidamente en el ámbito de la justicia concejil.

Un tipo de relación que adquirió especiales matices fue la mantenida entre los obispos de Cuenca y los concejos y vasallos de sus señoríos jurisdiccionales, en los cuales el obispo tenía potestad para nombrar a los oficiales concejiles, administrar justicia y cobrar determinados tributos a sus vasallos. Esta potestad señorial en ocasiones dio lugar a importantes conflictos entre el obispo y sus vasallos, debiendo destacarse los graves y violentos incidentes protagonizados a mediados del siglo XIV en los señoríos de Pareja y Casasana por el obispo don García, quien al parecer había mandado ejecutar a quince de sus vasallos ${ }^{91}$. En la centuria siguiente, aunque sin revestir tanto relieve, los conflictos fueron constantes en todos los señoríos de la mitra conquense fundamentalmente a partir del pontificado de Fray Lope de Barrientos, prolongándose hasta comienzos del siglo XVI, y estuvieron motivados por toda una serie de nuevas imposiciones tributarias que los obispos exigieron a sus vasallos ${ }^{92}$.

Pero, junto a esta importante presencia del elemento conflictivo, también hubo algunos momentos de manifiesta colaboración entre la Iglesia conquense y los concejos, en particular el de la ciudad de Cuenca, lo que sucedió de manera especialmente acusada durante el pontificado del obispo Barrientos, quien tuvo durante amplios periodos de tiempo la guarda de Cuenca por mandato regio, encabezando en 1447 y 1449, en unión de las tropas del concejo, la defensa de la ciudad contra don Diego Hurtado de Mendoza y sus parciales, e interviniendo posteriormente en numerosos asuntos específicamente concejiles.

Las relaciones de la Iglesia con la nobleza conquense - tanto alta como baja nobleza - se plasmarían en el ámbito de lo conflictivo y en el de la mutua cooperación ${ }^{93}$. En cuanto al primero de ellos, hay que señalar que una buena parte de los conflictos económicos que se produjeron estuvieron motivados por los muchos impedimentos que algunos nobles ponían al cobro $\mathrm{o}$ arrendamiento de los diezmos pertenecientes al cabildo catedralicio, y

\footnotetext{
${ }^{91}$ ASVat., Reg. Vat. 145, ff. 200v-201r.

${ }^{92}$ AGS, Registro General del Sello, 13-II-1494, f. 156.

${ }^{93}$ Esta cuestión la desarrollo con amplitud en mi trabajo Las relaciones Iglesia-Nobleza en el obispado de Cuenca durante la Baja Edad Media, "En la España Medieval", 20 (1997), pp. 281-319.
} 
también por la simple negativa a su pago, siendo sobre todo a partir del siglo XIV cuando comienzan a ser frecuentes este tipo de conflictos, que se desarrollarían con una particular intensidad en algunos señoríos del Marquesado de Villena, como Alarcón y Castillo de Garcimuñoz, por lo que muchas veces sería necesaria la mediación regia y del marqués de Villena.

Además de estos conflictos económicos, durante el siglo $\mathrm{XV}, \mathrm{y}$ dentro del contexto de las agitaciones nobiliarias tan características de los reinados de Juan II y Enrique IV, también se produjeron importantes y violentos conflictos de marcada significación social y política entre el obispo y cabildo catedralicio y algunos destacados representantes te la alta nobleza conquense.

Por un lado, en el año 1429 los latentes enfrentamientos de bandos existentes en la ciudad de Cuenca alcanzarían un especial grado de violencia, contando con una relevante participación eclesiástica. Pero ante todo hay que destacar la defensa de la ciudad de Cuenca en favor de Juan II y contra el noble conquense don Diego Hurtado de Mendoza y sus aliados que en 1447 y 1449 realizó al frente de las tropas concejiles el obispo Barrientos, quien durante los alzamientos proalfonsinos de 1464-1465 también se pondría a la cabeza del movimiento de defensa de la autoridad regia de Enrique IV contra el marqués de Villena don Juan Pacheco.

Otra importante manifestación de las relaciones mantenidas entre la Iglesia de Cuenca y la nobleza es la que vino dada por la destacada presencia de algunos representantes de la alta y mediana nobleza conquense ocupando cargos de diverso relieve en el cabildo catedralicio, siendo éste un proceso que, si bien sus raíces se remontan al siglo XIII, es sobre todo a partir de la centuria siguiente, y más acusadamente durante el siglo XV, cuando se produce de manera mucho más intensa.

Finalmente, hay que señalar que estas relaciones con la nobleza también se desarrollarían muchas veces en el marco del mecenazgo hacia la Iglesia por parte de algunos miembros destacados del estamento nobiliario, tanto en la ciudad de Cuenca como en el resto del obispado, reflejándose frecuentemente dicho mecenazgo en la realización por parte de algunos nobles de donaciones diversas en favor de la Iglesia y fundación de capellanías, aniversarios e incluso nuevos centros monásticos, lo que no sólo poseía una significación religiosa, sino que también venía a ensalzar el elevado rango social de determinados personajes. Así, entre las familias que otorgaron este mecenazgo cabe destacar a los Albornoz, Carrillo, Hurtado de Mendoza, Pacheco, Cabrera, Chirino y Álvarez de Toledo. 
Ya para terminar, no queda sino hacer una breve alusión a las relaciones mantenidas entre la Iglesia conquense y las comunidades judía y musulmana que habitaron en la ciudad y diócesis, relaciones en cuyo desarrollo no faltarían algunas ocasionales situaciones conflictivas más o menos intensas según los momentos, y tanto debido a factores económicos como religiosos.

\section{CONCLUSIÓN}

A lo largo de las páginas precedentes se ha analizado en sus líneas esenciales cuáles fueron las bases institucionales de la Iglesia de Cuenca durante la Edad Media, así como las relaciones de poder que se desarrollaron en el transcurso de los siglos medievales, constatándose de este modo hasta qué punto resulta imposible entender la Historia de la Iglesia al margen de una sociedad que condiciona en grandísima medida el devenir de los hechos eclesiásticos.

El obispo era la cabeza y máxima autoridad de la jerarquía eclesiástica conquense, siguiéndole en importancia el cabildo catedralicio, auténtica élite eclesial fuertemente jerarquizada en su seno, muchos de cuyos miembros pertenecían a la oligarquía urbana conquense. En el siguiente puesto del escalafón eclesiástico se encontraba el clero beneficiado parroquial, mientras que el abundante contingente de clérigos no beneficiados ocupaba el puesto de menor relieve dentro de esta jerarquía. A todo ello, por supuesto, hay que añadir una importante representación del clero regular que irá en aumento a medida que avance la Baja Edad Media.

Dentro de esta estructura eclesiástica fuertemente institucionalizada hemos constatado todo el amplio abanico de relaciones de poder que se desarrollaron durante la Edad Media. Las relaciones mantenidas con la Monarquía castellana han constituído el primer ámbito de estudio, demostrándose cómo sobre la diócesis de Cuenca a medida que avanzó la Baja Edad Media la Monarquía fue ejerciendo un control cada vez mayor, al igual que también sucedió en el conjunto de la Iglesia del reino, observándose asimismo una presencia cada vez más acusada de eclesiásticos conquenses en la política y gobernación del reino.

Las relaciones de orden intraeclesial constituyen otro ámbito fundamental: relaciones con el Papado; con la archidiócesis de Toledo; relaciones de los obispos de Cuenca con el cabildo catedralicio; relaciones del obispo y cabildo con el clero diocesano, así como las de orden interno 
entre los clérigos parroquiales; relaciones con algunos monasterios de religiosos; y relaciones del obispo y cabildo con las Órdenes militares de la diócesis, fundamentalmente la de Santiago. De este modo, mediante el análisis de estas relaciones, se ha podido constatar la gran diversidad de situaciones de poder que se daban en el seno de la propia Iglesia.

El último campo de estudio ha venido dado por el análisis de las relaciones mantenidas con la sociedad local conquense: relaciones Iglesiaconcejos, relaciones con la nobleza conquense $y$, finalmente, con las comunidades judía y musulmana.

En conclusión, desde el mismo momento de su fundación, y de forma mucho más intensa a medida que avanzó la Baja Edad Media, la Iglesia de Cuenca quedaría plenamente integrada dentro de todo un complejo sistema de relaciones de poder cuya caracterización vino, en gran medida, definida por la propia dinámica evolutiva de la Iglesia occidental y de la sociedad conquense y castellana bajomedieval, teniendo dichas relaciones su ámbito de plasmación concreta en el marco de una estructura eclesiástica institucionalizada que, de manera ineludible, quedaría también constituída en estructura de poder sólidamente incorporada a la sociedad del momento. Esto era algo perfectamente explicable en una civilización como la medieval, en la que casi todos los ámbitos de la realidad cotidiana estaban impregnados en mayor o menor medida por el Cristianismo, constituyendo ello uno de los rasgos más explícitamente caracterizadores del devenir histórico de aquellos siglos.

\section{RÉSUMÉ}

Le présent article renferme, en synthèse serrée, les conclusions essentielles de mes recherches sur l'Église de Cuenca pendant le Moyen Âge (XII'-XV' siècles), dont l'évolution historique est toujours analysée en relation étroite avec la société du moment. Pour cela, après avoir étudié ses bases essentielles économiques et institutionnelles -cest-à-dire, l’Évêque, le chapitre, le clergé paroissial, les ordres religieuses- on analyse les rapports de pouvoir dans lesquels l'Église de Cuenca a été mêlée tout au long du Moyen Âge: ses rapports avec la Monarchie castillane; on analyse les rapports ecclésiastiques avec la Papauté, entre les differents niveaux hiérarchiques du clergé de Cuenca, et avec les ordres religieuses et militaires; et, finalement, on analyse ses rapports avec la société laïque (noblesse et conseils municipaux). Ainsi, on prouve comment l'Église de Cuenca s'est constituée en estructure de pouvoir institutionnalisée et pleinement intégrée dans la société du moment. 


\section{SUMMARY}

This article contains, in a summary, the basic conclusions of my research works in the Church of Cuenca during the Middle Ages (12th-15th centuries). I always analyse its historic evolution bearing in mind the society of that time. For that reason, after studying the main institutional basis - bishop, cathedral chapter, parochial clergy - and economical ones, I analyse the power relations in which the Church of Cuenca was involved in the Middle Ages: relationship with the Castilian Monarchy, ecclesiastic relationship - with the Papacy, among the different hierarchical levels of the Church of Cuenca and with the religious and Military Orders - and with the lay society (nobility and councils). This is the way to prove that the Church of Cuenca was set as a structure of an institutionalised power and that it was fully integrated in the society of its time. 